\title{
Hydrodynamic Performance Improvement of Double-Row Floating Breakwaters by Changing the Cross-Sectional Geometry
}

\author{
Meysam Rajabi $\mathbb{D D}^{1}$ and Hassan Ghassemi $\mathbb{D D}^{2}$ \\ ${ }^{1}$ Department of Civil and Environmental Engineering, Amirkabir University of Technology, 424 Hafez Ave. P.O. Box 15875-4413, \\ Tehran, Iran \\ ${ }^{2}$ Department of Maritime Engineering, Amirkabir University of Technology, 424 Hafez Ave. P.O. Box 15875-4413, Tehran, Iran
}

Correspondence should be addressed to Meysam Rajabi; meysam1995@aut.ac.ir

Received 14 April 2021; Accepted 1 June 2021; Published 14 June 2021

Academic Editor: Giacomo Falcucci

Copyright (c) 2021 Meysam Rajabi and Hassan Ghassemi. This is an open access article distributed under the Creative Commons Attribution License, which permits unrestricted use, distribution, and reproduction in any medium, provided the original work is properly cited.

\begin{abstract}
This paper is presented to develop the hydrodynamic performance of double-row floating breakwater (FBW) by changing crosssectional geometry in the high wave periods. The ANSYS-AQWA software is employed for the present calculations, which is a potential-based boundary element method (BEM). The rectangular moored pontoons in the single- and double-row types are selected, and the results of the wave transmission coefficient and response amplitude operator (RAO) are presented and compared. The numerical results showed good agreement with experimental data at different wavelengths, wave height, and the distance between double-row FBWs. Then, the performance results of FBWs for five shapes (rectangular, $\pi$-shaped, plus-shaped, triangular-shaped, and box-shaped) in the wave transmission coefficient, RAO, and mooring line tension are presented and compared to each other. The results showed that the plus-shaped FBW has a better performance in reducing wave transmission than other shapes. In waves with long periods, the performance of $\pi$-shaped, triangular-shaped, and box-shaped FBWs is reduced, and the rectangular FBW loses its efficiency. Overall, the plus-shaped FBW has preferable performance regarding RAO response, mooring tension, and wave transmission.
\end{abstract}

\section{Introduction}

Breakwaters are structures that are designed to protect coastal installations from the danger of waves and their impact. There are two types of breakwaters: floating and fixed. Although fixed breakwaters always provide higher protection performance than floating breakwaters (FBWs), the FBW is an affordable solution that can be used effectively in coastal calm conditions. In recent years, utilizing FBW has received much attention. In the cases of deep water, poor geotechnical conditions, severe sediment conditions, and high seabed slope, this type of breakwater is the best option.

In the wave-structure interaction, the wave field around the structure is divided into three parts (reflected wave, damped wave due to turbulence, and transmitted wave). The amount of transmitted waves determines the performance of the FBWs. A structure that can reflect more waves has better performance. In the analysis of FBWs, one of the essential parameters which are commonly analyzed is the wave transmission coefficient. This parameter is the ratio of transmitted wave height to the incident wave height, which determines the FBW performance [1]. Some of the structural and hydrodynamic parameters are effective in wave transmission coefficient, which has been studied by many researchers. McCartney examined four types of floating breakwater and concluded that the moored pontoon breakwater had superior performance [2]. Sannasiraj et al. used a two-dimensional finite element model to study the FBW and concluded that the arrangement of the mooring does not affect the float performance [3]. Lee et al. proposed a method to obtain the response of a floating pontoon quay. They showed that pontoon's movements were proportional to the size, draft, and mooring characteristics [4]. Wang and Sun made a new experimental model of the porous floating 
breakwater. This model was fabricated with large numbers of diamond-shaped blocks to reduce transmitted waves. They concluded that the porous floating breakwater could reduce incident wave height [5]. Pena et al. experimented with several models to calculate wave transmission coefficients and concluded that the width of the pontoon is a useful parameter to determine the breakwater performance [6]. He et al. introduced a type of FBW with pneumatic chambers. They showed that the installation of pneumatic chambers to the FBW would improve the performance of the system [7]. Martin et al. provided a computational fluid dynamic (CFD) numerical model to analyze the effect of the mooring system on the FBW [8]. Cho analyzed a rectangular FBW with the vertical porous plates and concluded that selected porosity plates help reduce the transmission coefficients [9]. Peng et al. investigated waves' interactions with submerged FBWs moored using a numerical model [10].

All studies in [2-23] were done on the single-row FBW, and these studies showed that the width of FBW is effective in its performance. Some of the studies to increase the performance of the structure have used double-row breakwaters. Ji et al. studied the hydrodynamic behavior of a double-row pontoon floating breakwater using physical and numerical models. They found that the new FBW has a better performance for the high-period and large-amplitude waves [1]. Ji et al. did some experiments about single- and double-row breakwater and then concluded that, in general, the double-row breakwater system has better performance [24]. Ji et al., in an experimental study, analyzed the hydrodynamic behaviors of double-row rectangular pontoon FBW and concluded that double-row FBWs significantly reduce the transmission coefficients [25]. Hitherto, much research has been done on rectangular FBWs. Moreover, the excellent performance of rectangular FBW is proven in wave periods of less than 5 seconds $[14,26]$. The performance of FBWs in high-wave periods is a problem that has been inadequately investigated. Researchers also concluded that double-row FBWs are efficient in reducing the wave transmission coefficient [1, 24, 25].

However, using double-row breakwaters increases the costs. This subject destroys the cost-effectiveness characteristic of FBWs. The FBW shape has a high impact on its performance, which determines added mass, radiation damping, length, width, draft, and mass parameters. Therefore, the shape of the FBWs can change their performance. This study intends to investigate the hydrodynamic performance of double-row moored FBWs with different shapes at low wave periods compared with high wave periods using a numerical model. In fact, it has been tried to improve FBW performance in higher wave periods by changing its shape. In Section 2, the governing equations and the numerical method used in this study are described. In Section 3, the numerical model of this study has been validated using an experimental model in terms of the various conditions in determining the wave transmission coefficients and RAO response motions. In Section 4, five different shapes of the FBWs are modeled under a specific wave with different periods. Then their performance in wave transmission coefficient, RAO responses, and mooring tension are presented and compared. Finally, the results of this study are presented in Section 5.

\section{Theoretical Formulation}

In analyzing hydrodynamic problems, fluid is usually assumed to be Newtonian and incompressible. Such an assumption is acceptable for water. Therefore, the fluid flow governed by a set of elliptic partial differential equations is known as the Navier-Stokes (N-S) equations. Due to the large dimensions of the structure, the viscosity of the fluid is negligible. So, water is assumed to be inviscid everywhere. Such an assumption, together with the assumption of incompressibility, results in an ideal fluid and the N-S equations reduced to Euler equations, in which all viscous stresses are eliminated. Assuming that the flow is irrotational, the governing equations reduce to a linear partial differential equation called the Laplace equation. Such a flow is known as potential flow. The boundary element method (BEM) has the advantage of converting a domain integration problem to a surface integration problem, and this may improve computational efficiency. However, BEM's application is most prevalent in solving the Laplace equation, where the volume-surface transformation, ensured by Green's theorem, is complete [27]. The Laplace equation calculations have provided acceptable results assuming the incompressible fluid and the irrotational flow in the wavestructure interaction problems [28]. Here, the purpose is the analysis of the effect of wave environmental force on pontoon FBWs. In the analysis of the force of water waves on marine structures that are large in proportion to the wavelength, it is necessary to consider the wave-structure interaction. The configuration of a floating pontoon breakwater interacting with a linear wave is shown in Figure 1, where diffraction and radiation problems have been applied. In this study, ANSYS-AQWA commercial software has been used for the hydrodynamic analysis of floating structures in the time and frequency domain, and the method and technic of this application to solve problems are presented.

2.1. Governing Equations. In order to describe the fluid flow field around a floating structure, the velocity potential is defined as [29]

$$
\Phi(\vec{X}, t)=A \varphi(\vec{X}) e^{-i \omega t}
$$

where $A$ is the incident wave amplitude, $\omega$ is the wave frequency, $t$ is the time, and $\vec{X}=(x, y, z)$ is the location relative to fixed reference axes (FRA). Here, using the usual symbol of floating Rigid Motions, three rotational and three translational motions of the body center of gravity are incited by an incident wave with unit amplitude:

$$
\begin{cases}X_{j}=u_{j}, & (j=1,2,3), \\ X_{j}=\theta_{j-3}, & (j=4,5,6) .\end{cases}
$$

Here, the total potential $\varphi(\vec{X})$ can be considered as a sum of three components: incident wave $\left(\varphi_{I}\right)$, diffracted wave $\left(\varphi_{D}\right)$, 


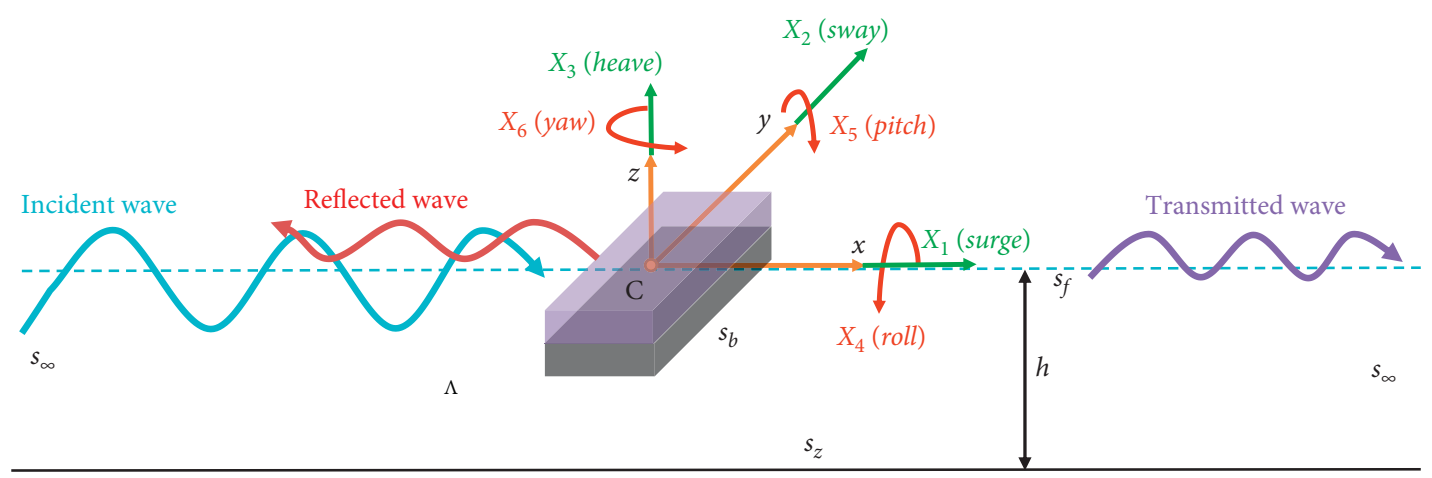

FiguRe 1: Definition sketch for theoretical analysis.

and radiated wave $\left(\varphi_{R}\right)$, and all three potentials satisfy the Laplace equation. This is mathematically represented as

$$
\varphi(\vec{X}) e^{-i \omega t}=\left[\varphi_{I}+\varphi_{D}+\sum_{j=1}^{6} \varphi_{R j} X_{j}\right] e^{-i \omega t},
$$

where $\varphi_{I}$ is the first-order incident wave potential with unit wave amplitude, $\varphi_{D}$ is the corresponding diffraction wave potential, and $\varphi_{R j}$ is the radiation wave potential due to the $j$ th motion with unit motion amplitude.

The velocity potential function is $\Phi(\vec{X}, t)$, time-independent term is $\varphi(\vec{X})$, according to linear hydrodynamic theory for incompressible and inviscid fluid, and irrotational fluid flow is described by the following equations:

(i) The Laplace equation in the fluid domain $(\Lambda)$ [30]:

$$
\nabla^{2} \varphi(x, y, z)=\frac{\partial^{2} \varphi}{\partial x^{2}}+\frac{\partial^{2} \varphi}{\partial y^{2}}+\frac{\partial^{2} \varphi}{\partial z^{2}}=0,
$$

(ii) Linear free surface $\left(s_{f}\right)$ on $z=0$ :

$$
-\omega^{2} \varphi+g \frac{\partial \varphi}{\partial z}=0
$$

(iii) Body surface conditions $\left(s_{b}\right)$ :

$$
\frac{\partial \varphi}{\partial n}=\left\{\begin{array}{cl}
-i \omega n_{j}, & \text { for radiation potential, } \\
-\frac{\partial \varphi}{\partial n}, & \text { for diffraction potential, }
\end{array}\right.
$$

(iv) Seabed surface condition $\left(s_{z}\right)$ at $z=-h$ :

$$
\frac{\partial \varphi}{\partial z}=0
$$

(v) For far-field condition $\left(s_{\infty}\right)$ where $\sqrt{x^{2}+y^{2}}$ $\longrightarrow \infty$,

$$
|\nabla \varphi| \longrightarrow 0
$$

In this study, as described in Introduction, The ANSYSAQWA software is employed to solve the velocity potential, which is based on the potential-based BEM. In addition to the boundary conditions mentioned in the previous section, in the fluid domain, also the below boundary condition is satisfied [31]:

$$
\nabla^{2} G(\vec{X}, \vec{\xi}, \omega)=\frac{\partial^{2} G}{\partial x^{2}}+\frac{\partial^{2} G}{\partial y^{2}}+\frac{\partial^{2} G}{\partial z^{2}}=\delta(\vec{X}-\vec{\xi}) .
$$

where $X \in \Lambda, \xi \in \Lambda, \vec{\xi}=(\xi, \eta, \zeta)$ is the location of a source on the FBW wetted surface, and $\delta(\vec{X}-\vec{\xi})$ is the Dirac function, which is described as

$$
\delta(\vec{X}-\vec{\xi})=\left\{\begin{array}{lll}
0, & \text { where, } & \vec{X}-\vec{\xi} \neq 0, \\
\infty, & \text { where, } & \vec{X}-\vec{\xi}=0 .
\end{array}\right.
$$

Then, according to the Dirac function, Green's function can be signified as

$$
\begin{aligned}
G(\vec{X}, \vec{\xi}, \omega) & =\frac{1}{r}+\frac{1}{r_{2}}+\int_{0}^{\infty} \frac{2(k+v) e^{-k h} \cosh [k(z+h)] \cosh [k(\zeta+h)]}{k \sinh (k h)-v \cosh (k h)} j_{0}(k R) \mathrm{d} k \\
& =i 2 \pi \frac{\left(k_{0}+v\right) e^{-k_{0} h} \cosh \left[k_{0}(z+h)\right] \cosh \left[k_{0}(\zeta+h)\right]}{\sinh \left(k_{0} h\right)+k_{0} h \cosh \left(k_{0} h\right)-v h \sinh \left(k_{0} h\right)} j_{0}\left(k_{0} R\right),
\end{aligned}
$$

where $J_{0}$ is the first kind of Bessel function, and 


$$
\begin{aligned}
R & =\sqrt{(x-\xi)^{2}+(y-\eta)^{2}}, \\
r & =\sqrt{R^{2}+(z-\zeta)^{2}}, \\
r_{2} & =\sqrt{R^{2}+(z+\zeta-2 h)^{2}}, \\
v & =\frac{\omega^{2}}{g}, \\
k_{0} \tanh \left(k_{0} h\right) & =v
\end{aligned}
$$

where $k=(2 \pi / L)$ is the wavenumber, $\omega$ is the wave frequency, $L$ is the wavelength, and $g$ is the gravitational acceleration.

Here, the velocity potential of radiation and diffraction waves is defined as a Fredholm integral equation of the second kind by Green's theorem.

$$
\begin{aligned}
c \varphi(\vec{X}) & =\int_{S_{0}}\left\{\varphi(\vec{\xi}) \frac{\partial G(\vec{X}, \vec{\xi}, \omega)}{\partial n(\vec{\xi})}-G(\vec{X}, \vec{\xi}, \omega) \frac{\partial \varphi(\vec{\xi})}{\partial n(\vec{\xi})}\right\} d S, \\
c & = \begin{cases}0, & \vec{X} \notin \Lambda \bigcup S_{0}, \\
2 \pi, & \vec{X} \in S_{0}, \\
4 \pi, & \vec{X} \in \Lambda .\end{cases}
\end{aligned}
$$

Then, the fluid potential is defined as

$$
\varphi(\vec{X})=\frac{1}{4 \pi} \int_{S_{b}} \sigma(\vec{\xi}) G(\vec{X}, \vec{\xi}, \omega) \mathrm{d} S,
$$

where $\vec{X} \in \Lambda \cup S_{b}$.

In equation (14), using the hull surface boundary condition given by equation (6), the source strength over the mean wetted hull surface is defined as

$$
\frac{\partial \varphi(\vec{X})}{\partial n(\vec{X})}=-\frac{1}{2} \sigma(\vec{X})+\frac{1}{4 \pi} \int_{S_{b}} \sigma(\vec{\xi}) \frac{\partial G(\vec{X}, \vec{\xi}, \omega)}{\partial n(\vec{X})} \mathrm{d} S
$$

where $\vec{X} \in S_{b}$.

2.2. Equation of Motion and RAOs. The obtained solutions for the diffraction and radiation problems can be combined with the equation of motion of the floating FBW system to analyze the dynamic responses of the structural system in both time and frequency domains.

In the frequency domain, the structural equation of motion is given by

$$
\left[-\omega^{2}\left(M_{s}+M_{a}^{\prime}\right)-i \omega C \prime+K_{h y s}^{\prime}+K_{a}\right]\left[X_{j m}\right]=\left[F_{j m}^{\prime}\right],
$$

where $M_{a}^{\prime}$ and $M_{s}$ are the total added mass matrices and the total structural mass, respectively, and the coefficient $C^{\prime}$ is the hydrodynamic damping matrix. $K_{a}$ and $K_{h y s}^{\prime}$ are the additional structural stiffness matrices and the assembled hydrostatic stiffness, respectively, and $F_{j m}{ }^{\prime}$ represents the total Froude-Krylov and diffracting forces and moments, where $m$ corresponds to the structure and $j$ pertains to the motion modes.

Then, the equation of motion in the time domain is expressed as

$$
M \ddot{X}(t)+C \dot{X}(t)+K X(t)=F(t),
$$

where $M$ is the added mass in the mass matrix and $C$ is the hydrodynamic damping in the damping matrix, and both of them are frequency-dependent, and $K$ is the total stiffness matrix. Here, according to the external force $(F(t))$, which has a constant amplitude, the equation of motion in the frequency domain cannot be straight converted into the time-domain equation. Therefore, by employing a convolution integral form, the equation of motion can be defined as follows [32]:

$$
\begin{aligned}
\left\{M_{s}+A_{\infty}\right\} \ddot{X}(t) & +c \dot{X}(t)+K X(t) \\
& +\int_{0}^{t} R(t-\tau) \dot{X}(\tau) \mathrm{d} \tau=F(t),
\end{aligned}
$$

where $A_{\infty}$ is the added mass matrix at the infinite frequency, $c$ is the damping matrix, including the results of the radiation damping, $R$ is the velocity impulse function matrix, and $K$ is the total stiffness matrix.

Also, the acceleration impulse function matrix can be used in the equation of motion as follows:

$$
\begin{aligned}
\left\{M_{s}+A_{\infty}\right\} \ddot{X}(t) & +c \dot{X}(t)+K X(t) \\
& +\int_{0}^{t} h(t-\tau) \ddot{X}(\tau) \mathrm{d} \tau=F(t) .
\end{aligned}
$$

The acceleration impulse function matrix can be determined as

$$
\begin{aligned}
h(t) & =-\frac{2}{\pi} \int_{0}^{\infty} B(\omega) \frac{\sin (\omega t)}{\omega} \mathrm{d} \omega \\
& =\frac{2}{\pi} \int_{0}^{\infty}\left\{A(\omega)-A_{\infty}\right\} \cos (\omega t) \mathrm{d} \omega,
\end{aligned}
$$

where $B(\omega)$ is the hydrodynamics damping matrix and $A(\omega)$ is the added mass matrix. By replacing the first- and second-order wave loads into equation (19), the equation of motion is obtained as

$$
\begin{aligned}
\left\{m \prime+A_{\infty}\right\} \ddot{X}(t)= & F^{(1)}(t)+F^{(2)}(t)+F_{t}(t)-c \dot{X}(t) \\
& -K X(t)-\int_{0}^{t} h(t-\tau) \ddot{X}(\tau) \mathrm{d} \tau,
\end{aligned}
$$

where $K$ is the total stiffness matrix, and it includes mooring stiffness and the linear hydrostatics, $F_{t}(t)$ is the mooring and articulation force, $F^{(1)}(t)$ is the first-order wave excitation force and moment, and $F^{(2)}(t)$ is the second-order wave excitation force. 
Response amplitude operator (RAO) is the motion of a floating structure in six degrees of freedom (surge, sway, heave, roll, pitch, and yaw) due to hydrodynamic wave force. RAOs are utilized as input data for calculations to determine the displacements, accelerations, and velocities at any given location on a marine floating structure. In general, RAO is calculated by the ratio of response amplitude of the FBW $\left(X_{j}\right)$ to the wave amplitude $\left(A_{i}\right)$ for linear motion and the ratio of response amplitude of the FBW to the wave slope $\left(\alpha_{i}\right)$ for rotational motion, which is defined as follows:

$$
\begin{aligned}
& \text { RAO }=\frac{X_{j}}{A_{i}}, \quad \text { where } X_{j}=u_{j}, \quad(j=1,2,3), \\
& \text { RAO }=\frac{X_{j}}{\alpha_{i}} \text {, where } X_{j}=\theta_{j-3}, \quad(j=4,5,6) .
\end{aligned}
$$

where $\alpha_{i}$ is the wave slope, $A_{i}$ is the wave amplitude, and $X_{j}$ is the response amplitude of FBW in rotational $\left(\theta_{j-3}\right)$ and displacement $\left(u_{j}\right)$ mode. ANSYS-AQWA analyzes linear algebraic equations to determine the harmonic response of the body to regular waves. These response characteristics are commonly referred to as RAOs and are dependent on wave amplitude.

2.3. Mooring System. In order to analyze the dynamics of the cable motion, many factors should be considered, such as the effects of cable mass, drag forces, inline elastic tension, and bending moment. The forces applied to the cable vary with time and, generally, the cables behave nonlinearly. The simulation of cable dynamics is needed to discretize cable along its length and assemble the mass and applied forces. Each mooring line is discretized as a series of Morison-type elements subjected to various external forces, as shown in Figure 2.

The general equations for the force and moment acting on the cable are expressed as follows:

$$
\begin{gathered}
\frac{\partial \vec{T}}{\partial s_{e}}+\frac{\partial \vec{V}}{\partial s_{e}}+\vec{w}+\vec{F}_{h}=m \frac{\partial^{2} \vec{R}}{\partial t^{2}}, \\
\frac{\partial \vec{M}}{\partial s_{e}}+\frac{\partial \vec{R}}{\partial s_{e}} \times \vec{V}=-\vec{q},
\end{gathered}
$$

where $\vec{R}$ is the position vector of the first node of the cable element, $\vec{T}$ is the tension force vector at the first node of the element, $\vec{M}$ is the bending moment vector at the first node of the element, $\vec{V}$ is the shear force vector at the first node of the element, $\vec{F}_{h}$ represents the external hydrodynamic loading vectors per unit length, $\vec{q}$ is the distributed moment loading per unit length, $m$ is the structural mass per unit length, $\vec{w}$ is the element weight per unit length, $D_{e}$ is the diameter of the element, and $\Delta s_{e}$ is the length of the element.

The bending moment and tension are relevant to the bending stiffness and the axial stiffness of the cable material defined as follows:

$$
\begin{aligned}
M^{\prime \prime} & =\mathrm{EI} \frac{\partial \vec{R}}{\partial s_{e}} \times \frac{\partial^{2} \vec{R}}{\partial s_{e}^{2}}, \\
T^{\prime \prime} & =\mathrm{EA} \varepsilon,
\end{aligned}
$$

where $M^{\prime \prime}$ is the bending moment of the cable, $T^{\prime \prime}$ is the tension of the cable, $\varepsilon$ is the axial strain of the element, EA is axial stiffness of cable, and EI is the bending stiffness of the cable.

2.4. Wave Transmission and Reflection Coefficients. The radiation wave energy transfer from the FBW causes the wave to pass through the structure. This energy transfer occurs in three ways, that is, the waves passing over the structure, the waves passing under the structure, and the waves created by the motion of the structure, as shown in Figure 3.

FBWs are designed to reduce wave transmission. So, as explained in Introduction, the primary and most effective parameter in determining the performance of FBWs is the wave transmission coefficient. The total wave energy per unit length of the FBW is straightly proportionate to the square of the wave height [33].

$$
H_{i}^{2}=H_{r}^{2}+H_{t}^{2},
$$

where $H_{i}$ is the incident wave height, $H_{t}$ is the transmitted wave height, and $H_{r}$ is the reflected wave height. The transmission coefficient is defined by $C_{t}=\left(H_{t} / H_{i}\right)$, while the reflection coefficient is defined by $C_{r}=\left(H_{r} / H_{i}\right)$. Hence, by replacing the defined parameters in equation (25), we can write the following equation:

$$
C_{t}^{2}+C_{r}^{2}=1
$$

In the real situation, due to the presence of viscous dissipation, equation (26) can be written as

$$
C_{t}^{2}+C_{r}^{2}+C_{d}^{2}=1 \text {, }
$$

where $C_{d}$ is the dissipation coefficient that is due to the viscous effects and the resulting energy loses, such as vortex shedding, friction, and wave breaking.

In this study, to calculate the wave transmission coefficient, the AQWA-GS module of ANSYS-AQWA is used. In this module, the results of calculations are displayed in different ways. After applying the wave load with determined characteristics, the wave amplitude can be calculated for different points of the domain. Then, by calculating the ratio of the amplitude of the incident wave to the amplitude of the wave behind the rear FBW, the wave transmission coefficient is obtained.

$$
C_{t}=\frac{A_{t}}{A_{i}}=\frac{H_{t}}{H_{i}} .
$$

where $A_{t}$ is the transmitted wave amplitude, $H_{i}$ is the transmitted wave height, $A_{i}$ is the incident wave amplitude, and $H_{i}$ is the incident wave height. 


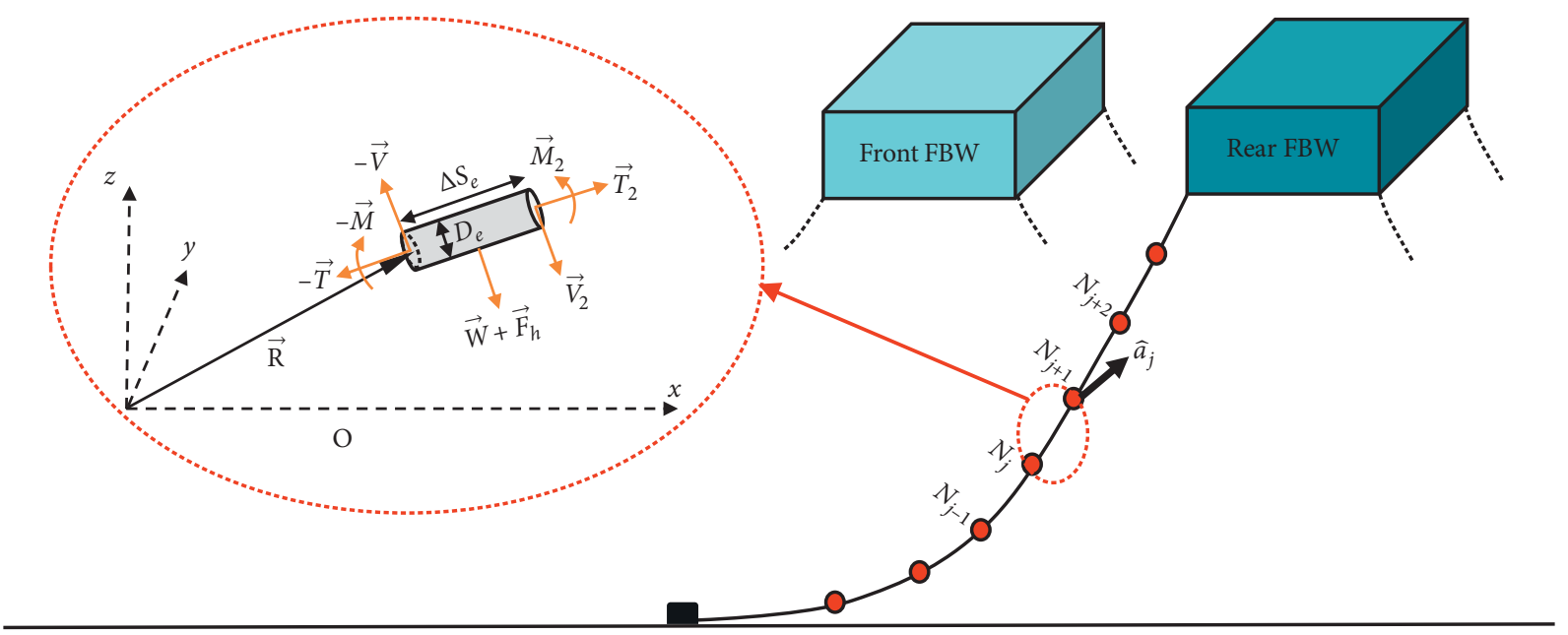

Figure 2: Forces and moments on a cable element.

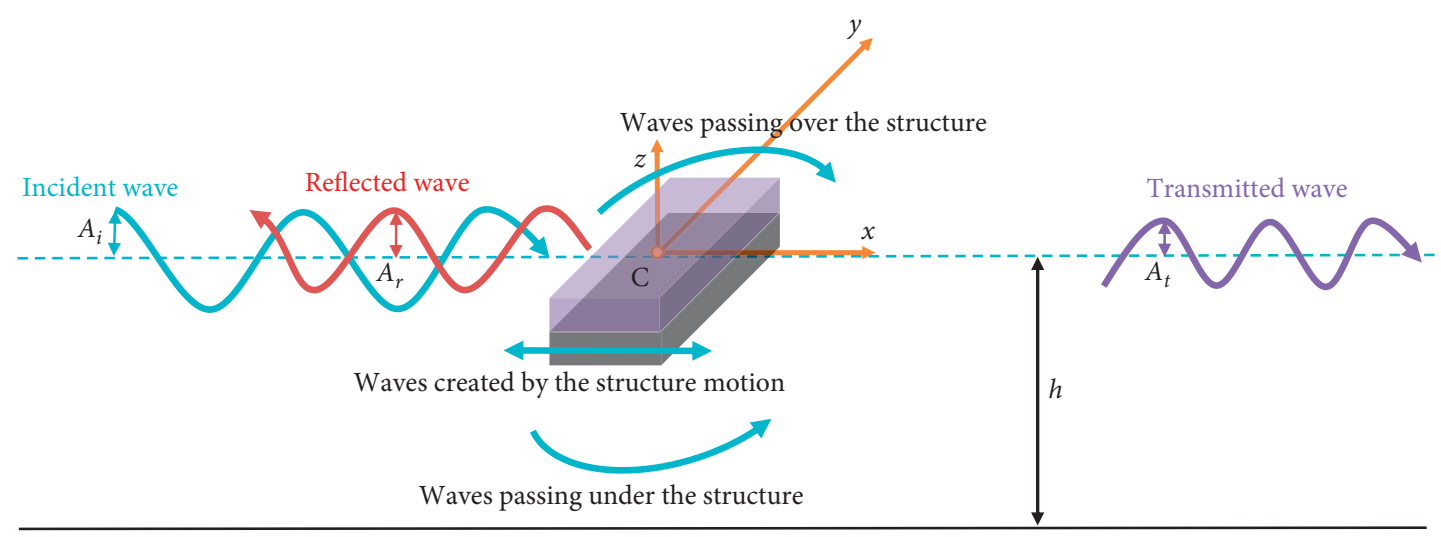

FIGURE 3: Sketch of wave energy transmission around FBW.

\section{Validation of the Numerical Model}

In this section, the numerical model is verified by an experimental model. The experimental model selected for the validation is the study of Ji et al. In that study, some experiments were performed on the single- and double-row breakwaters to determine their performance [24]. Figure 4 shows the sketch of the double-row FBWs experimental setup under the regular wave in a wave flume. The main model parameters and wave gauges characteristics of the experimental model are listed in Table 1 . The wave period $(T)$ is $1.1 \mathrm{~s}$, and the experimental wave heights $(H)$ are between 0.075 and $0.175 \mathrm{~m}$. The distances between doublerow FBW (S) are set as $2.5,5,7.5$, and $10 \mathrm{~m}$. The mooring line length is $1.6 \mathrm{~m}$ with a line density of $0.63 \mathrm{~kg} / \mathrm{m}$ where in the numerical model a nonlinear catenary cable is used. The numerical model of the experimental model is shown in Figure 5.

In Figures 6-8, the results of numerical and experimental analyses are presented. Figures 6 and 7 show the wave transmission coefficients $\left(C_{t}\right)$ versus $(L / B)$ and $(H / B)$ under different $(S / B)$. In these results, $L$ is the wavelength, $B$ is the width of FBW, and $S$ is the distance between FBWs. As shown in these figures, the numerical results are in good agreement with experimental data. The effect of $(H / B)$ is not significant on $C_{t}$, while $(L / B)$ is affected on $C_{t}$. Figure 8 shows the surge, heave, and pitch RAO of double-row FBWs and single-row FBW against $(H / B)$ under different $(S / B)$. It should be mentioned that the pitch RAO is defined by degree per meter. For all cases, the wave period is $1.1 \mathrm{~s}$, and the wave height is $0.1 \mathrm{~m}$ and $0.15 \mathrm{~m}$. As observed in the results, there is a relatively good agreement between the numerical results and experimental data. The wave height is not significantly affected by the wave transmission, while the increase of the wavelength is significantly caused to rise in the wave transmission coefficient. Regarding the RAO, increasing the ratio of $\mathrm{H} / \mathrm{B}$ has reduced all the surge, heave, and pitch motions. The effect of $(S / B)$ in heave RAO is minimal, but, in surge and pitch, RAO can be affected. It is pointed out that double-row FBW is better than the single-row FBW regarding wave transmission. The reason is that the turbulence caused by the interaction between FBWs and waves diffracts more wave energy. The next reason is that FBW can be considered as a roam pool. 


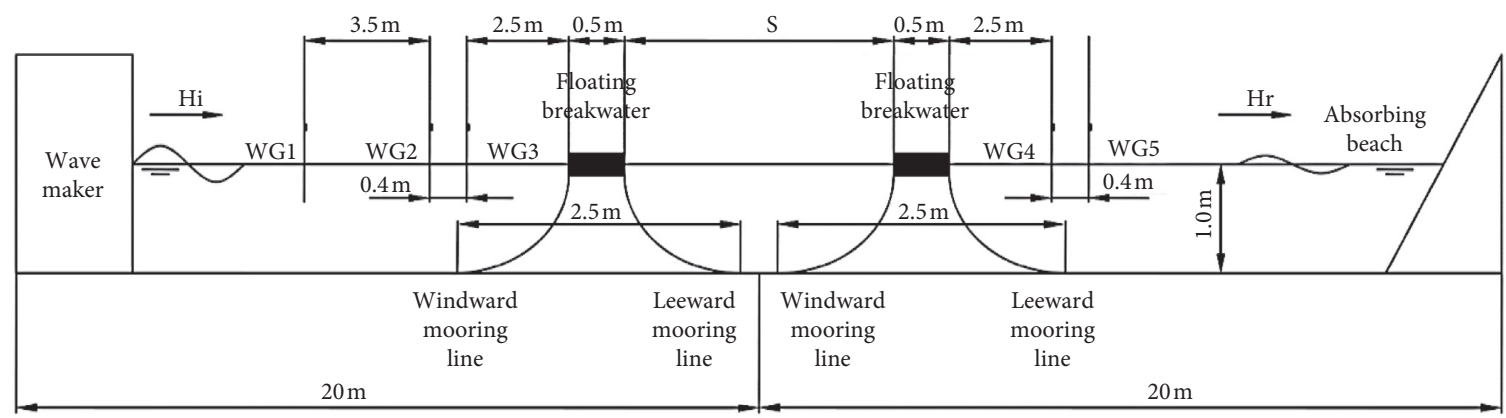

FIGURE 4: Sketch of double-row FBWs of the experimental setup [24].

TABle 1: Main parameters of the experimental model [24].

\begin{tabular}{|c|c|c|}
\hline \multirow{5}{*}{ Wave gauges (single-row FB) } & WG1 and WG2 & $350(\mathrm{~cm})$ \\
\hline & WG2 and WG3 & $40(\mathrm{~cm})$ \\
\hline & WG3 and model & $250(\mathrm{~cm})$ \\
\hline & Model and WG4 & $250(\mathrm{~cm})$ \\
\hline & WG4 and WG5 & $40(\mathrm{~cm})$ \\
\hline \multirow{5}{*}{ Wave gauges (double-row FBs) } & WG1 and WG2 & $350(\mathrm{~cm})$ \\
\hline & WG2 and WG3 & $40(\mathrm{~cm})$ \\
\hline & WG3 and model 1 & $250(\mathrm{~cm})$ \\
\hline & Model 2 and WG4 & $250(\mathrm{~cm})$ \\
\hline & WG4 and WG5 & $40(\mathrm{~cm})$ \\
\hline \multirow{7}{*}{ Main model parameters } & Length & $760(\mathrm{~mm})$ \\
\hline & Width & $500(\mathrm{~mm})$ \\
\hline & Height & $200(\mathrm{~mm})$ \\
\hline & Draft & $100(\mathrm{~mm})$ \\
\hline & Mass & $19.1(\mathrm{~kg})$ \\
\hline & Roll inertia & $0.558\left(\mathrm{~kg} \cdot \mathrm{m}^{2}\right)$ \\
\hline & Gravity center above the bottom & $100(\mathrm{~mm})$ \\
\hline
\end{tabular}

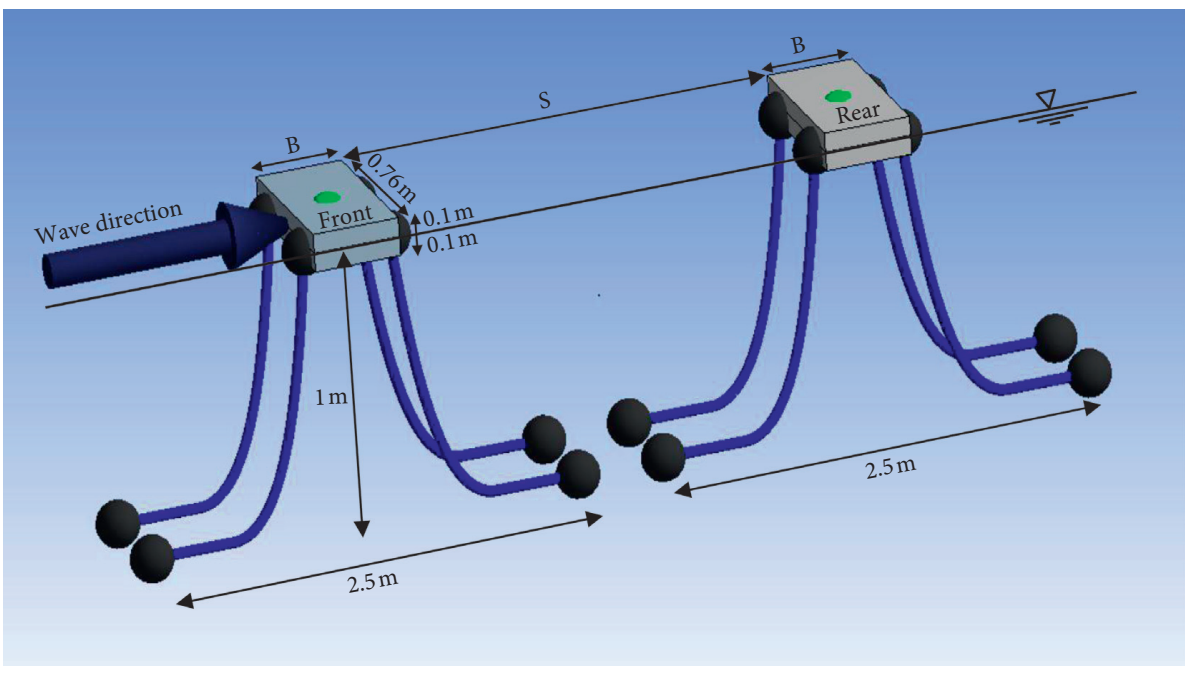

Figure 5: The numerical model of double-row FBW to validation. 

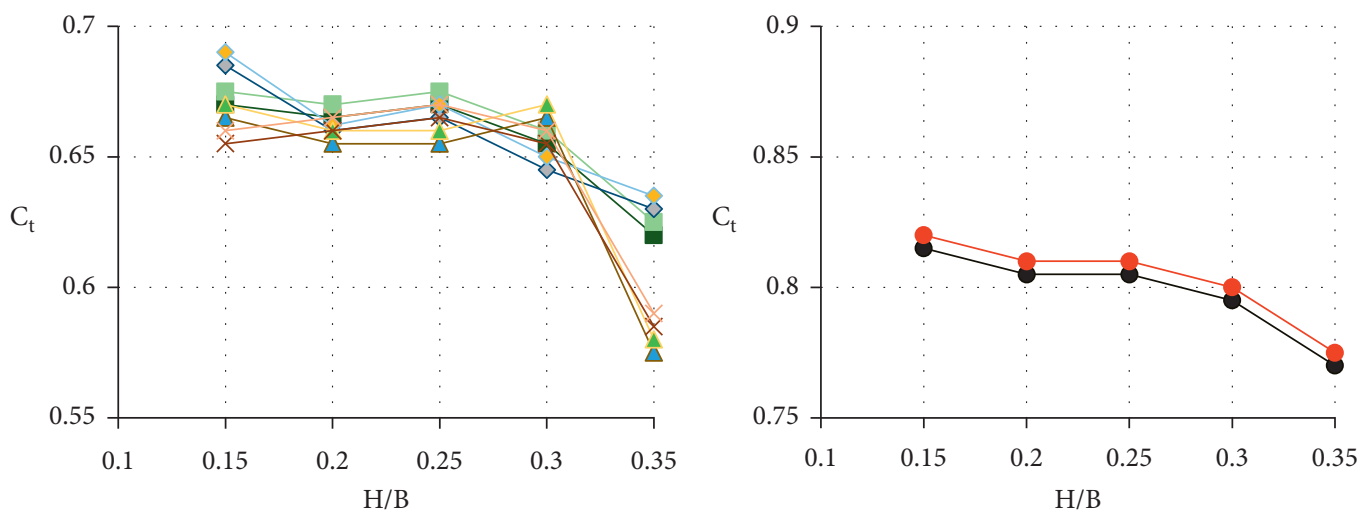

$$
\begin{array}{ll}
\text { Present } & \text { Ji, } 2019 \\
\neg \text { Numerical }(\mathrm{S} / \mathrm{B}=5) & -\operatorname{EXP}(\mathrm{S} / \mathrm{B}=5) \\
\prec \text { Numerical }(\mathrm{S} / \mathrm{B}=10) & -\operatorname{EXP}(\mathrm{S} / \mathrm{B}=10) \\
\neg \operatorname{Numerical}(\mathrm{S} / \mathrm{B}=15) & -\operatorname{EXP}(\mathrm{S} / \mathrm{B}=15) \\
\nsucc \operatorname{Numerical}(\mathrm{S} / \mathrm{B}=20) & \succ \operatorname{EXP}(\mathrm{S} / \mathrm{B}=20)
\end{array}
$$

(a)

$$
\begin{array}{ll}
\text { Present } & \text { Ji, } 2019 \\
\rightarrow-\text { Numerical (single) } & \longrightarrow \text { EXP (single) }
\end{array}
$$

(b)

FIgURe 6: Comparison of wave transmission coefficient $\left(C_{t}\right)$ versus $(H / B)$ under different $(S / B)$ of double-row (a) and single-row (b) FBWs ( $T=1.1 \mathrm{~s})$.

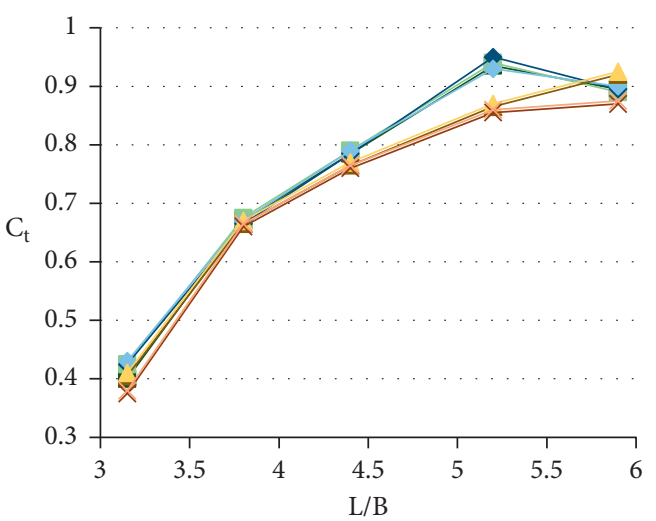

$$
\begin{array}{ll}
\text { Present } & \mathrm{Ji}, 2019 \\
-\operatorname{Numerical}(\mathrm{S} / \mathrm{B}=5) & -\operatorname{EXP}(\mathrm{S} / \mathrm{B}=5) \\
-\operatorname{Numerical}(\mathrm{S} / \mathrm{B}=10) & -\operatorname{EXP}(\mathrm{S} / \mathrm{B}=10) \\
-\operatorname{Numerical}(\mathrm{S} / \mathrm{B}=15) & -\operatorname{EXP}(\mathrm{S} / \mathrm{B}=15) \\
\leftarrow \operatorname{Numerical}(\mathrm{S} / \mathrm{B}=20) & \succ \operatorname{EXP}(\mathrm{S} / \mathrm{B}=20)
\end{array}
$$

(a)

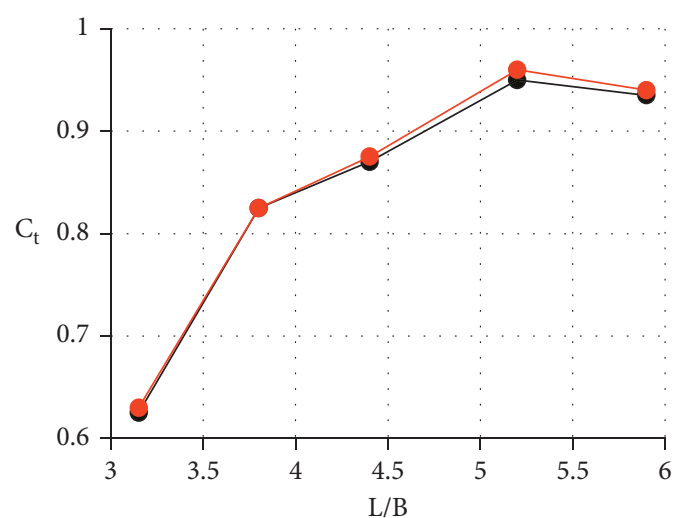

$$
\begin{array}{ll}
\text { Present } & \text { Ji, } 2019 \\
\text { - } \text { Numerical (single) } & \rightarrow-\text { EXP (single) }
\end{array}
$$

FIGURE 7: Continued. 


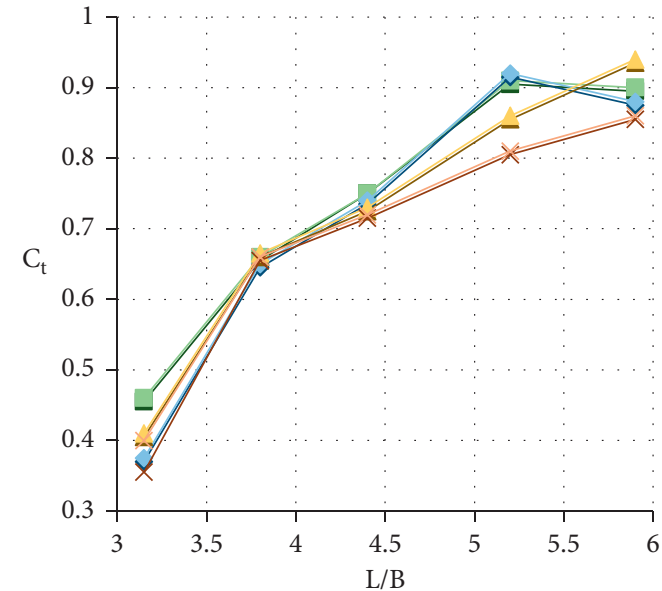

$$
\begin{array}{ll}
\text { Present } & \text { Ji, } 2019 \\
-\operatorname{Numerical}(\mathrm{S} / \mathrm{B}=5) & -\operatorname{EXP}(\mathrm{S} / \mathrm{B}=5) \\
-\operatorname{Numerical}(\mathrm{S} / \mathrm{B}=10) & -\operatorname{EXP}(\mathrm{S} / \mathrm{B}=10) \\
-\operatorname{Numerical}(\mathrm{S} / \mathrm{B}=15) & -\operatorname{EXP}(\mathrm{S} / \mathrm{B}=15) \\
-\operatorname{Numerical}(\mathrm{S} / \mathrm{B}=20) & \leftarrow \operatorname{EXP}(\mathrm{S} / \mathrm{B}=20)
\end{array}
$$

(c)

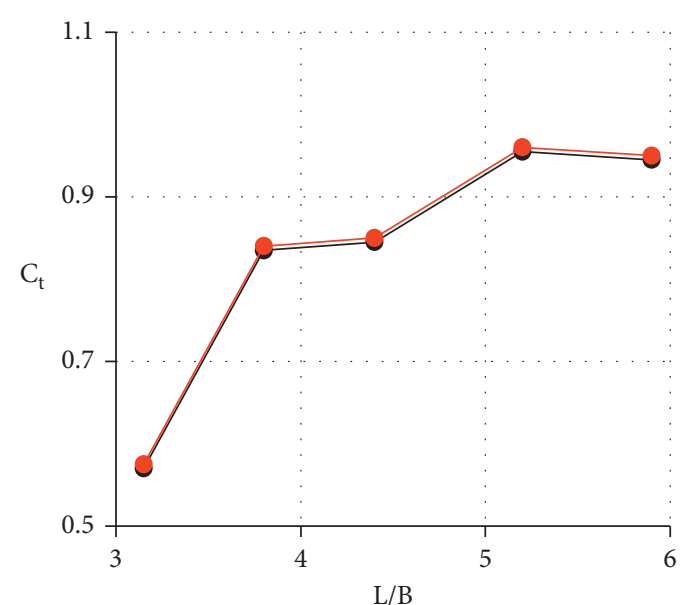

$$
\begin{array}{ll}
\text { Present } & \text { Ji, } 2019 \\
\rightarrow-\text { Numerical (single) } & \rightarrow \text { EXP (single) }
\end{array}
$$

(d)

Figure 7: Comparison of wave transmission coefficient $\left(C_{t}\right)$ versus $(L / B)$ under different $(S / B)$ : (a) double-row FBW, $H=0.1 \mathrm{~m}$; $(\mathrm{b})$ singlerow FBW, $H=0.1 \mathrm{~m}$; (c) double-row FBW, $H=0.15 \mathrm{~m}$; (d) single-row FBW, $H=0.15 \mathrm{~m}$.

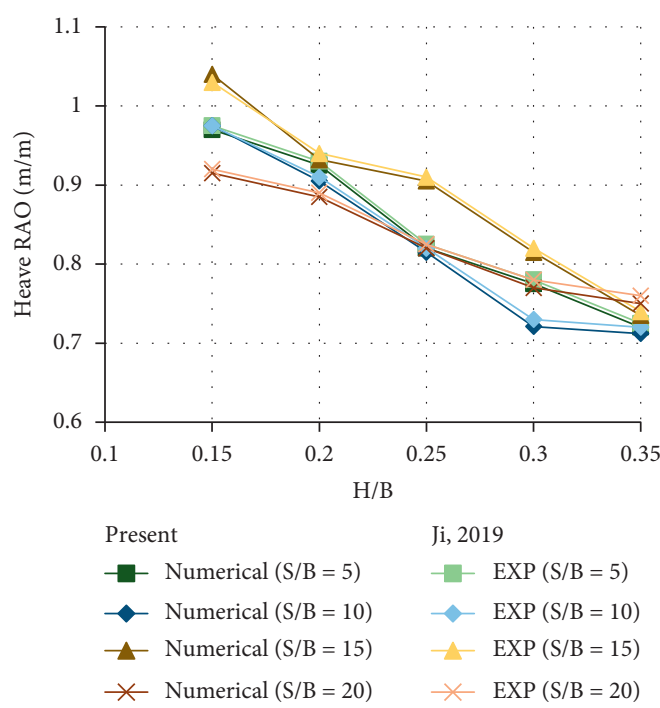

(a)

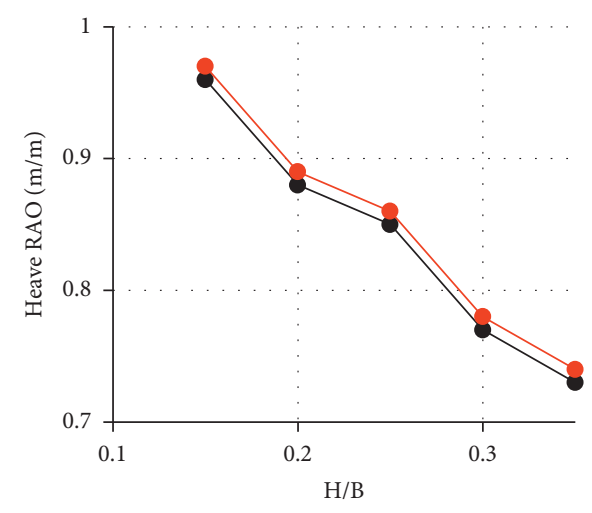

Present Ji, 2019

$\rightarrow$ - Numerical (single) $\rightarrow$ EXP (single)

(b)

Figure 8: Continued. 


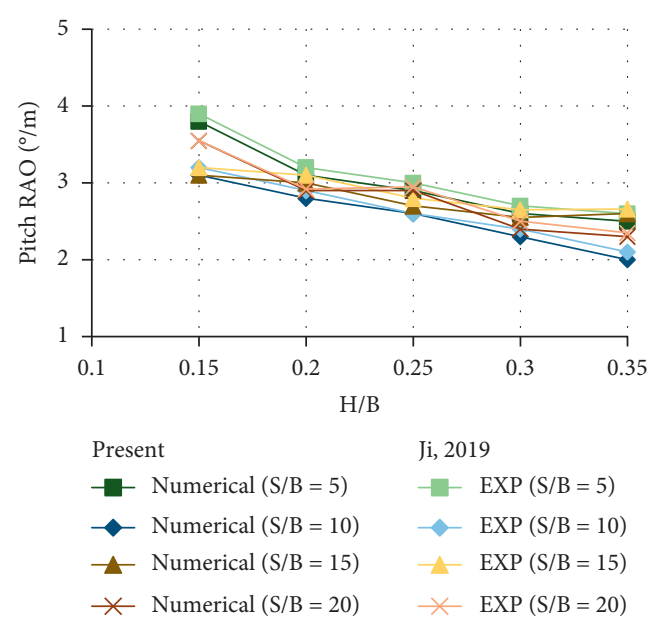

(c)

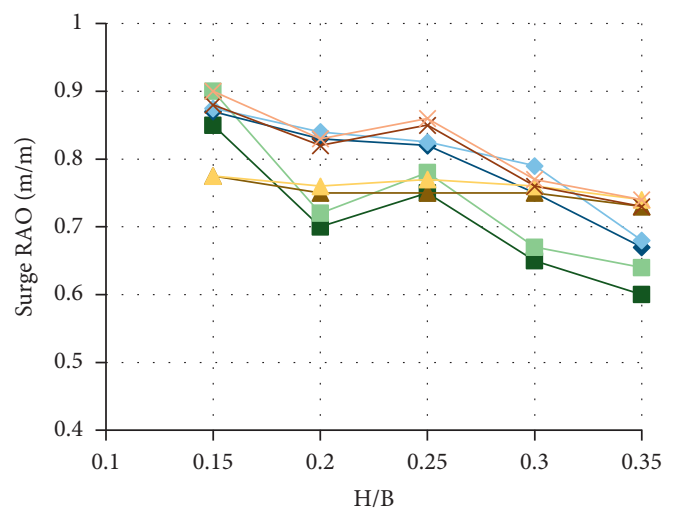

$\begin{array}{ll}\text { Present } & \mathrm{Ji}, 2019 \\ - \text { Numerical }(\mathrm{S} / \mathrm{B}=5) & -\operatorname{EXP}(\mathrm{S} / \mathrm{B}=5) \\ -\operatorname{Numerical}(\mathrm{S} / \mathrm{B}=10) & -\operatorname{EXP}(\mathrm{S} / \mathrm{B}=10) \\ \leftarrow \operatorname{Numerical}(\mathrm{S} / \mathrm{B}=15) & -\operatorname{EXP}(\mathrm{S} / \mathrm{B}=15) \\ \leftarrow \operatorname{Numerical}(\mathrm{S} / \mathrm{B}=20) & \succ \operatorname{EXP}(\mathrm{S} / \mathrm{B}=20)\end{array}$

(e)

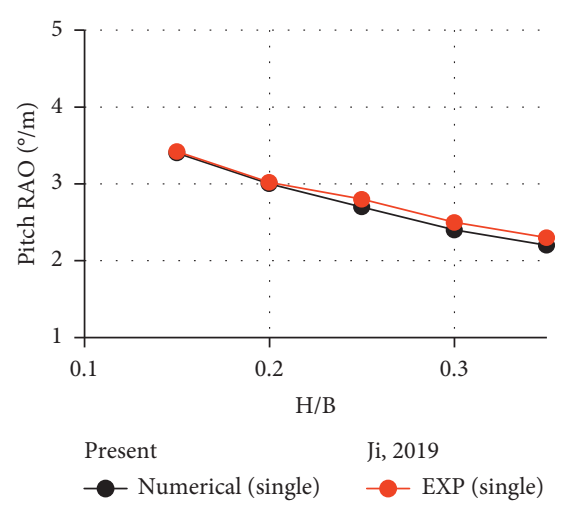

(d)

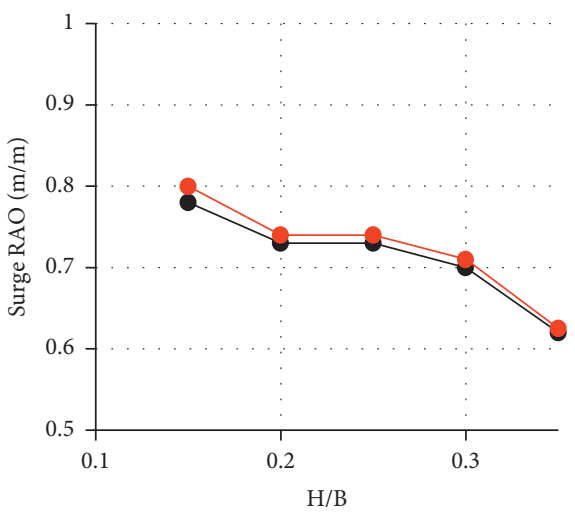

$$
\begin{array}{ll}
\text { Present } & \text { Ji, } 2019 \\
- \text { - Numerical (single) } & -
\end{array}
$$

(f)

Figure 8: Comparison of surge RAO versus $(H / B)$ under different $(S / B)$ of double-row $(a, c, e)$ and single-row $(b, d, f)$ FBWs $(T=1.1$ s).

\section{Results and Discussion}

4.1. Five Different Shapes of Double-Row FBWs. Five different shapes of the double-row FBWs are selected for checking the hydrodynamic performance in the wave transmission, as well as RAO of the three motions in the time and frequency domains. The shapes of FBWs were chosen based on the rectangular shape. So, without increasing the volume compared to the rectangle FBW (even less than rectangular FBW), it was tried to increase the draft of FBW in different modes. Table 2 shows the main dimensions of the five different shapes of the FBWs, moment of inertia, mooring properties, and environment constants. The box-shaped FBW is more massive than the others, and also it has more moment of inertia, while the rectangular shape has less mass and less moment of inertia. The main dimensions of all shapes (length, width, draft, and volume) are the same except the rectangular shape. In fact, the shapes are created by rectangular correction with an increase in the draft and a decrease in the volume to improve the performance of FBWs. Figure 9 shows five different shapes of the FBWs. Dimensions are also given for all shapes in the same figure. Mooring properties are presented in Table 2, which are equal in all shapes. Given that the front FBW is designed to increase the performance of the rear FBW, all calculations of the wave transfer coefficient, RAO, and mooring forces are applied to the rear FBW.

4.2. Wave Transmission Coefficient. As stated in Introduction, the wave transmission coefficient $\left(C_{t}\right)$ is an essential parameter in FBWs hydrodynamic performance. Lower value of $C_{t}$ provides better performance. There have been many studies on FBWs in the low-wave period. The increase in the wave period suddenly causes a reduction in the FBW performance. This section examines the effect of the geometry of FBW on its performance in the high periods. 
TABLE 2: Main dimensions and characteristics of the five different shapes of the FBWs.

\begin{tabular}{|c|c|c|c|c|c|c|}
\hline \multirow{2}{*}{ Specs } & & \multicolumn{5}{|c|}{ Types } \\
\hline & & Rectangular & Plus-shaped & $\pi$-Shaped & Triangular & Box-shaped \\
\hline \multirow{3}{*}{ Moment of inertia $\left(\mathrm{kg} \cdot \mathrm{m}^{2}\right)$} & $\mathrm{I}_{\mathrm{xx}}$ & $1.42 E+07$ & $1.64 E+07$ & $1.74 E+07$ & $1.54 E+07$ & $1.75 E+07$ \\
\hline & $\mathrm{I}_{y y}$ & $3.96 E+06$ & $3.83 E+06$ & $1.03 E+07$ & $4.17 E+06$ & $7.79 E+06$ \\
\hline & $\mathrm{I}_{z z}$ & $1.71 E+07$ & $1.89 E+07$ & $2.44 E+07$ & $1.75 E+07$ & $2.18 E+07$ \\
\hline \multicolumn{2}{|l|}{ Displacement (kg) } & 410000 & 471500 & 471500 & 430500 & 471500 \\
\hline \multicolumn{2}{|l|}{ Length $(\mathrm{m})$} & 20 & 20 & 20 & 20 & 20 \\
\hline \multicolumn{2}{|l|}{ Width (m) } & 10 & 10 & 10 & 10 & 10 \\
\hline \multicolumn{2}{|l|}{$\operatorname{Draft}(\mathrm{m})$} & 2 & 5 & 5 & 5 & 5 \\
\hline \multicolumn{2}{|l|}{ Volume $\left(\mathrm{m}^{3}\right)$} & 800 & 500 & 500 & 500 & 500 \\
\hline \multicolumn{2}{|l|}{ Environment constants } & \multicolumn{5}{|c|}{ Water depth $=30 \mathrm{~m}$, water density $=1025 \mathrm{~kg} / \mathrm{m}^{3}$, water size $x=500$, and water size $y=500$} \\
\hline \multirow{8}{*}{ Mooring properties } & & \multirow{8}{*}{\multicolumn{5}{|c|}{$\begin{array}{c}\text { Mass } / \text { unit length }=8.27 \mathrm{~kg} / \mathrm{m}^{3} \\
\text { Equivalent cross-sectional area }=0.002 \mathrm{~m}^{2} \\
\text { Maximum tension }=10000 \mathrm{~N} \\
\text { Stiffness }=5000000 \mathrm{~N} \\
\text { Equivalent diameter }=0.02 \mathrm{~m} \\
\text { Length of cable }=42 \mathrm{~m} \\
\text { Number of cables for each FBW }=4 \\
\text { Type of cable }=\text { nonlinear catenary section }\end{array}$}} \\
\hline & & & & & & \\
\hline & & & & & & \\
\hline & & & & & & \\
\hline & & & & & & \\
\hline & & & & & & \\
\hline & & & & & & \\
\hline & & & & & & \\
\hline
\end{tabular}

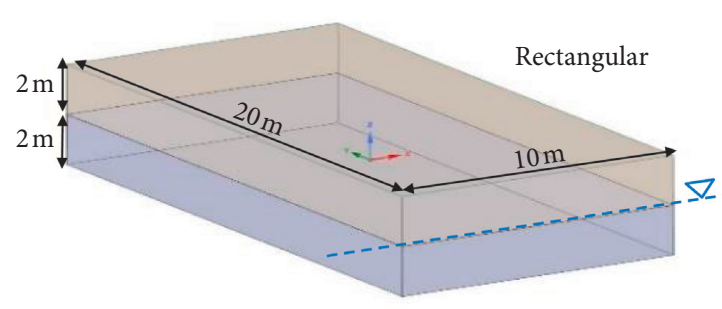

(a)

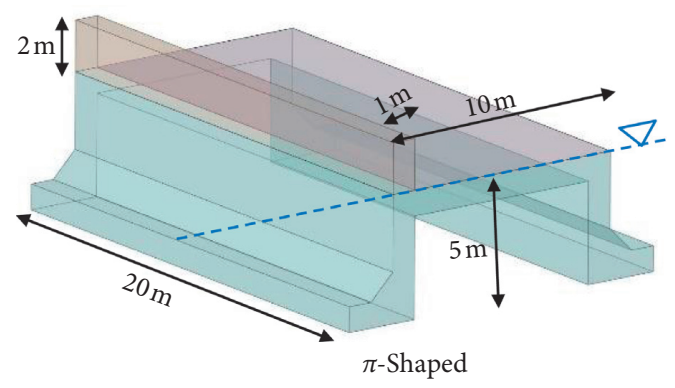

(c)

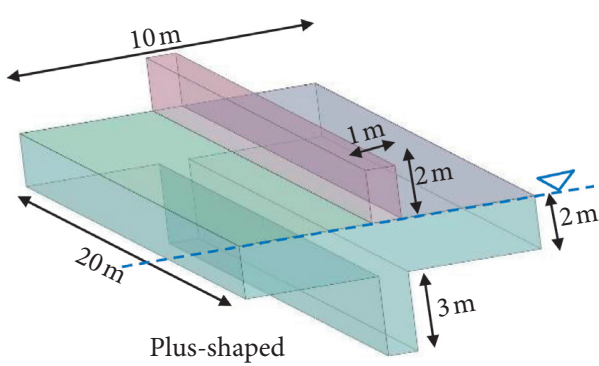

(b)

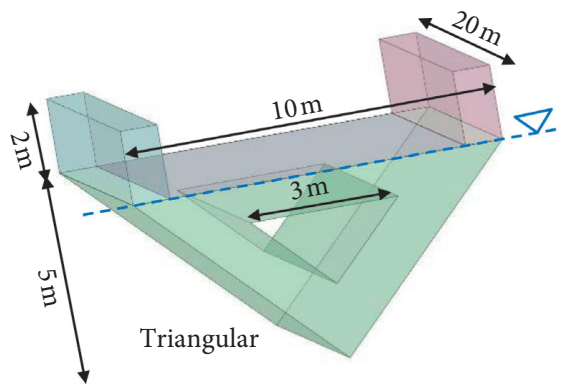

(d)

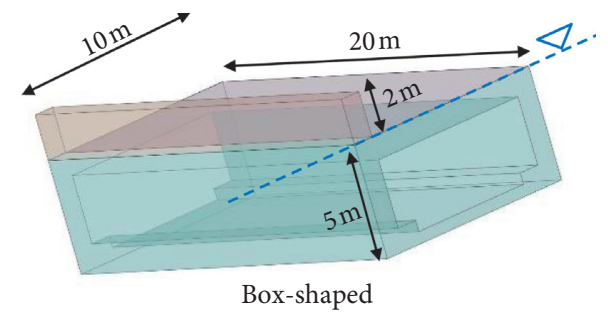

(e)

Figure 9: Five different shapes of the FBWs.

The wave transmission coefficient values for all shapes at periods 4 to $16 \mathrm{~s}$ are shown in Figure 10. In that figure, $C_{t}$ are compared at different wave periods and wave heights for all configuration types. The results show that the wave height has a low effect on the results of $C_{t}$. As shown in these figures, three zones are given (I, II, and III). Zone I shows the 


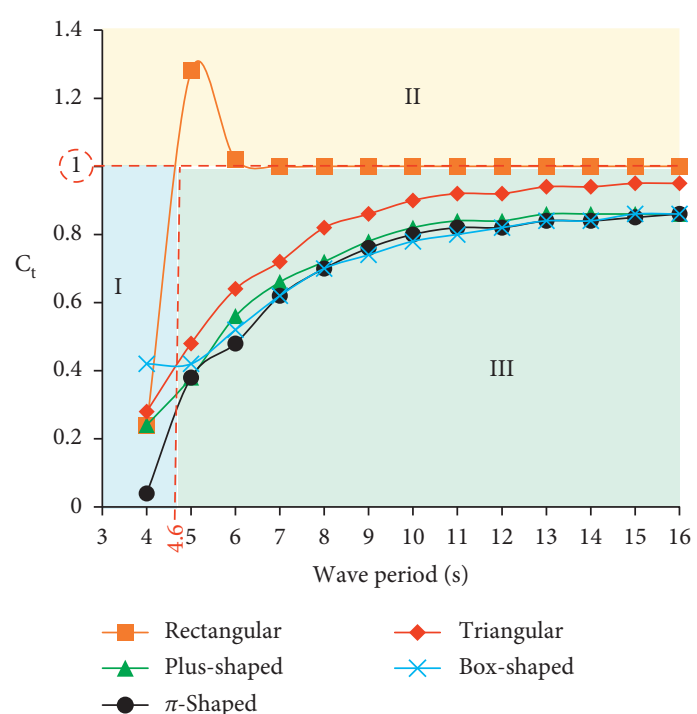

(a)

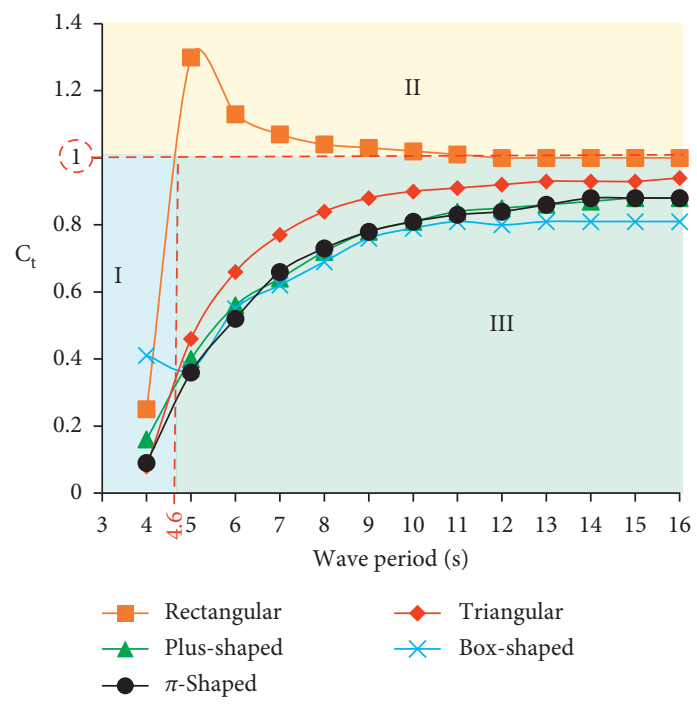

(c)

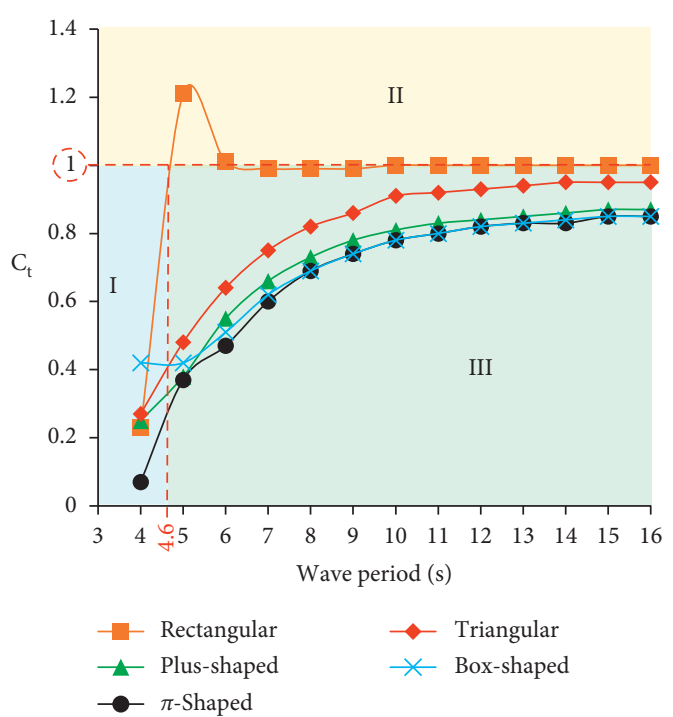

(b)

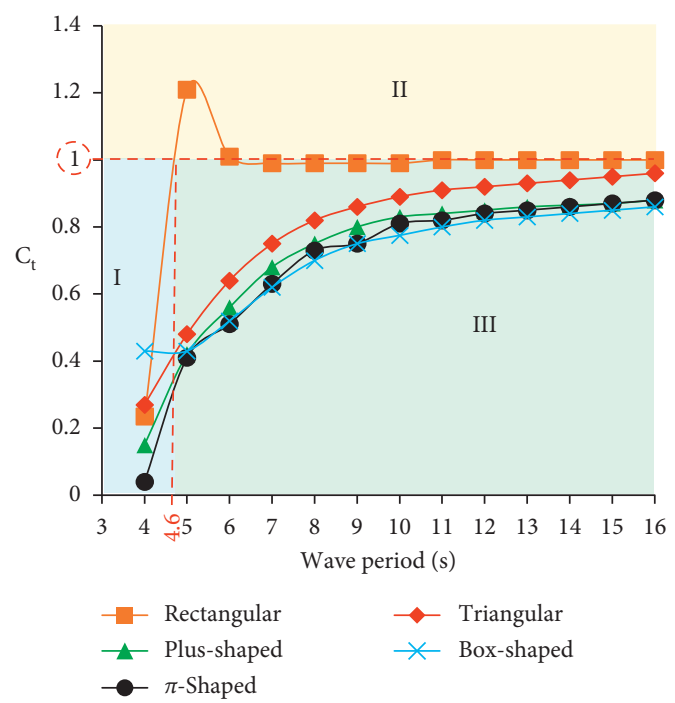

(d)

Figure 10: Wave transmission coefficients against wave period for different FBWs: (a) $H=1 \mathrm{~m}$, (b) $H=2 \mathrm{~m},(\mathrm{c}) H=3 \mathrm{~m}$, and (d) $H=4 \mathrm{~m}$.

FBWs performance at low-wave periods (less than $4.6 \mathrm{~s}$ ). All of the FBWs have a good performance with less wave transmission (ordinary performance). Zone II shows the inefficiency of FBWs, where, in this area, $C_{t}$ is more than one, which means that the amount of wave transmitted is at least equal to the accident wave. The FBW has no use in this area (loss of usability). In this zone, in addition to the incident wave passing up the FBW, sometimes some extra wave due to the structural motions is transmitted, which has an opposite effect. Zone III is the acceptable performance of FBWs at high-wave periods. Achieving excellent FBWs performance in this range of periods was the aim of this study (great performance). Rectangular-shaped FBW can be used for up to $4 \mathrm{~s}$ of wave period, and it does not work at the higher period. In the rectangular-shaped FBW, the significant increase of wave transmission coefficient in the $5 \mathrm{~s}$ period means that the transmitted wave height becomes larger than the incident wave height after the incident wave hits the FBW. $\pi$-Shaped, box-shaped, plus-shaped, and triangular FBWs give better performance compared to the rectangular-shaped FBW, and they have almost the same performance. However, it is observed that plus-shaped FBW has a more stable situation.

In order to indicate the wave pattern around the FBW, a wave is applied to the FBWs in $1 \mathrm{~m}$ amplitude and two periods of 4 and $10 \mathrm{~s}$. The 4 and $10 \mathrm{~s}$ periods were selected to simultaneously show the wave amplitude variations after hitting the FBW in both the high-wave and low-wave periods. Figures 11-13 show the wave pattern contours around all five shapes. The contours show the amplitudes of the waves around the FBW. As shown in these figures, to check the performance of the structure, a point $20 \mathrm{~m}$ behind the rear FBW (point C) was selected, and the wave amplitude was measured to calculate $C_{t}$. In Figure 11, rectangular FBW 


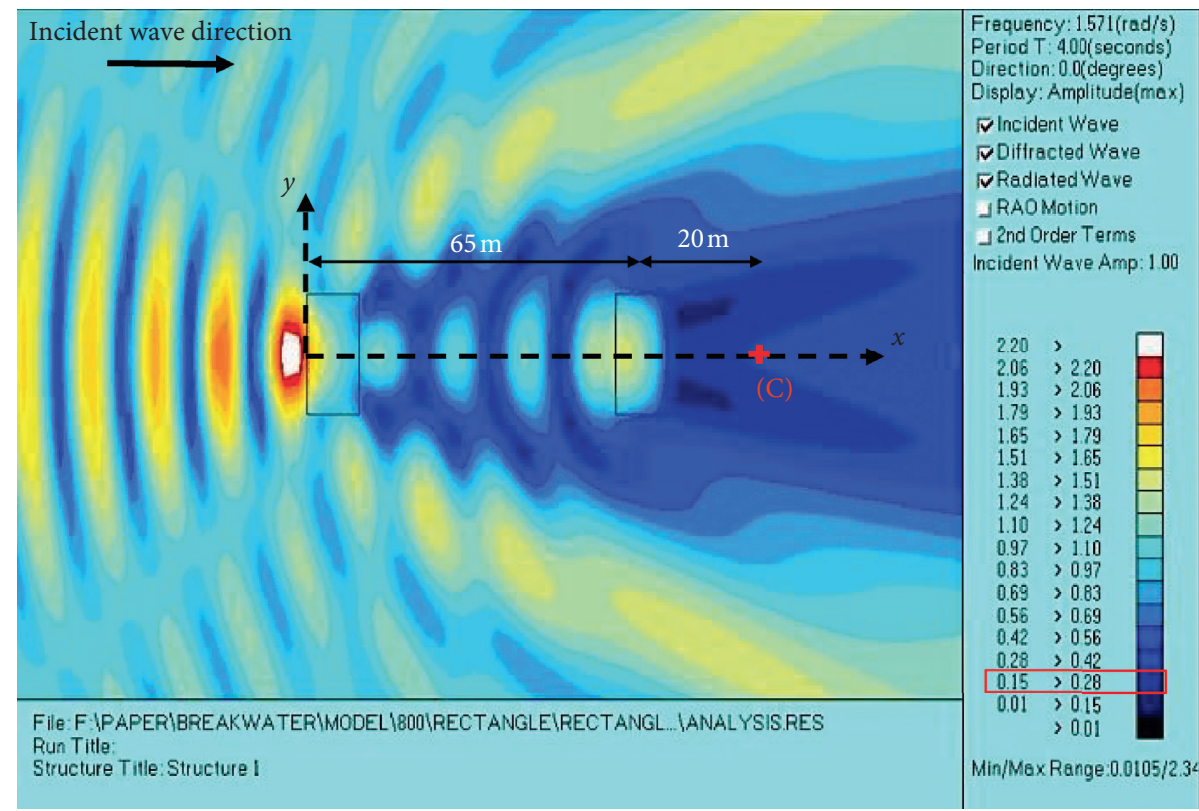

FIGURE 11: Wave pattern contour around rectangular-shaped FBW at low-wave period of $4 \mathrm{~s}$ (wave amplitude $A=1 \mathrm{~m}$ ); (C): the coordinates of the wave amplitude transferred: $(x, y, z)=(85,0,0)$.

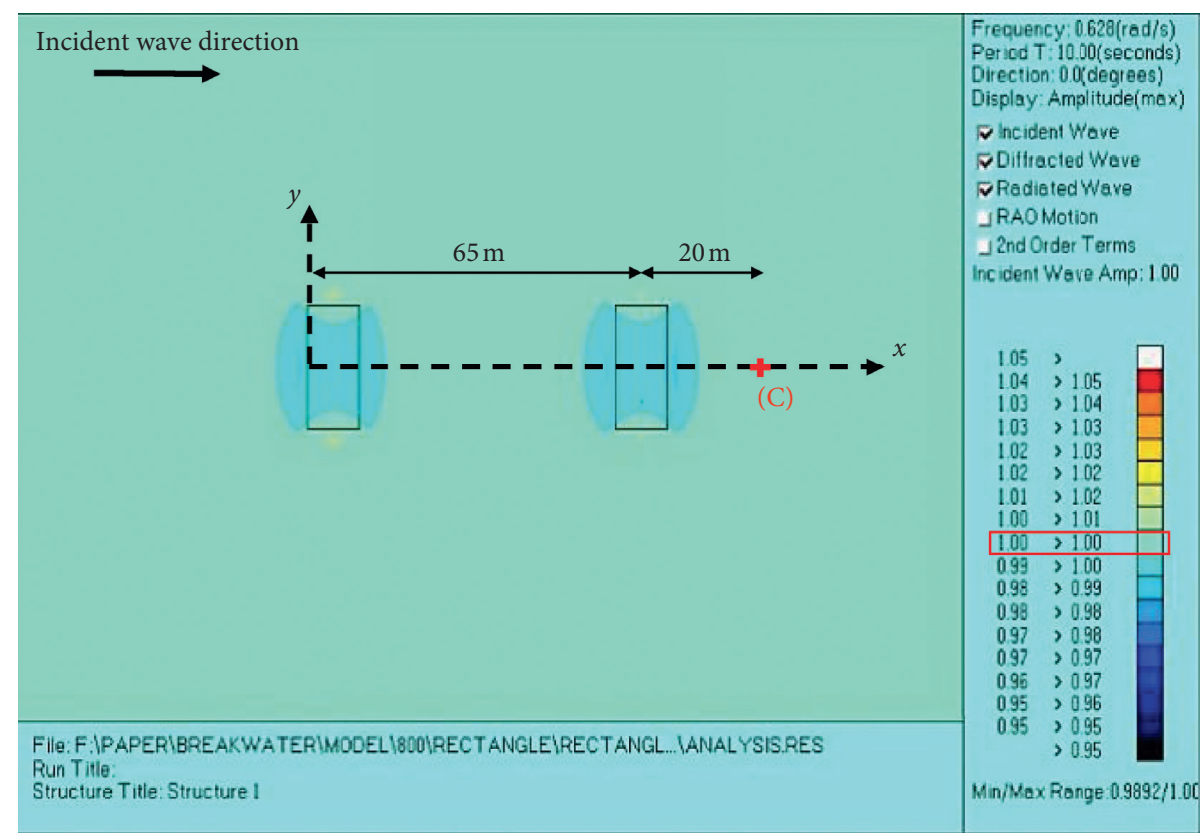

FIGURE 12: Wave pattern contour around rectangular-shaped FBW at high-wave period of $10 \mathrm{~s}$ (wave amplitude $A=1 \mathrm{~m}$ ); (C): the coordinates of the wave amplitude transferred: $(x, y, z)=(85,0,0)$.

contours show that, in the period of $4 \mathrm{~s}$, the FBW works well, and the wave amplitude behind the rear FBW (transmitted wave amplitude) is significantly reduced compared to the incident wave amplitude. But, in the period of $10 \mathrm{~s}$, as shown in Figure 12, contours show that the incident wave amplitude $(1 \mathrm{~m})$ and the transmitted wave amplitude are equal, and the FBW has lost its performance. Figure 13 shows the wave amplitude contours around $\pi$-shaped, box-shaped, plus-shaped, and triangular-shaped FBWs for two wave periods of $4 \mathrm{~s}$ and $10 \mathrm{~s}$. In this paper, in order to reduce the volume of results, these contours are not shown in detail as in Figures 11 and 12, but it is easy to realize the results with generalizing to these figures. As shown in Figure 13, the FBWs have maintained their performance in the period of 


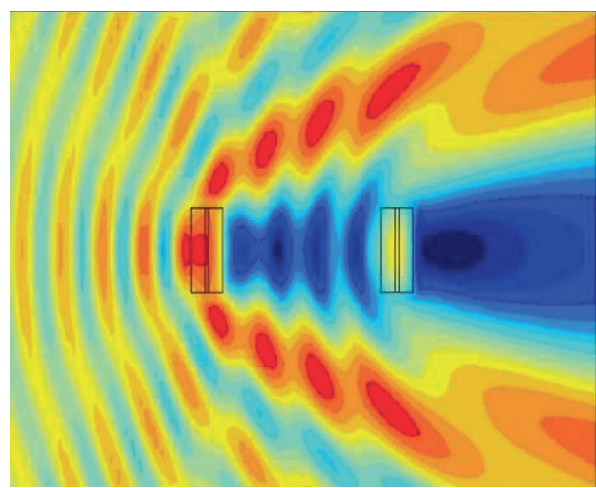

(a)

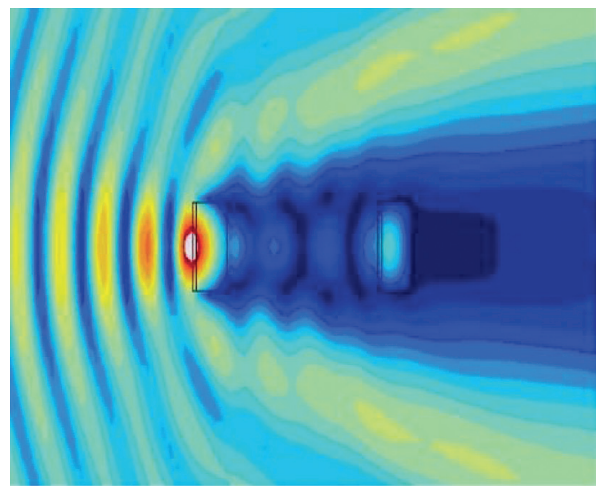

(c)

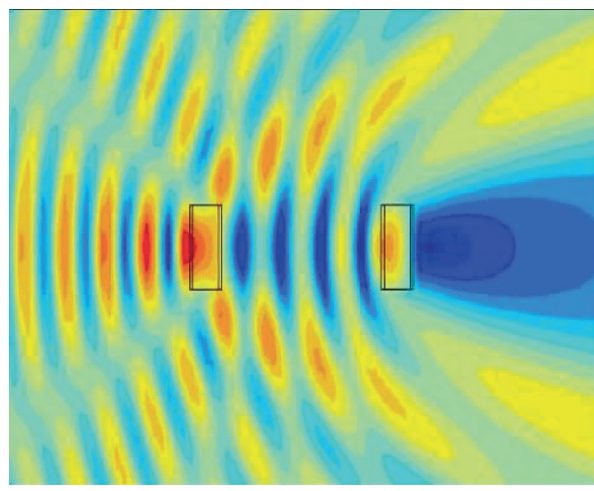

(e)

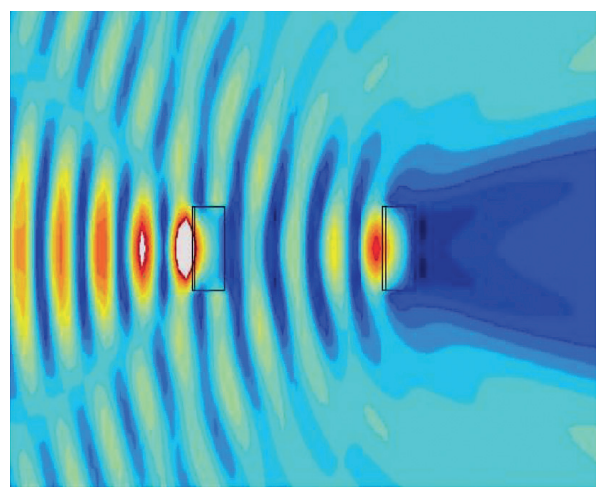

(g)

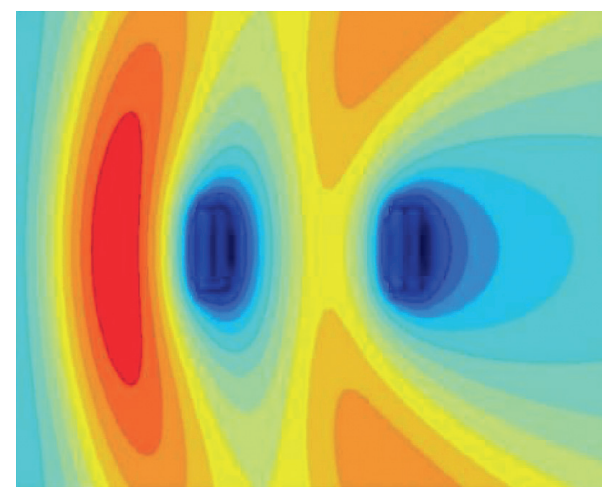

(b)

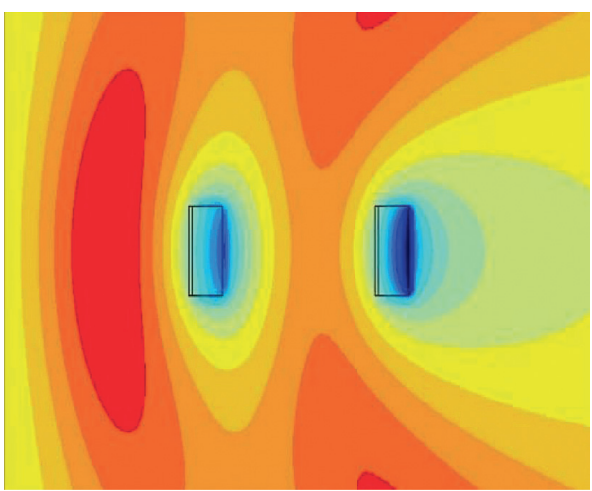

(d)

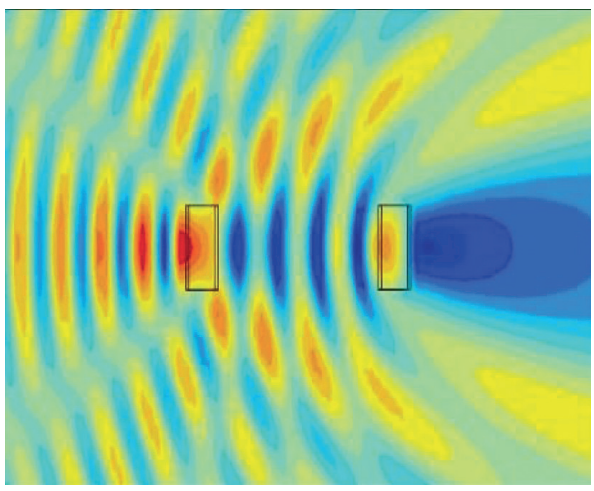

(f)

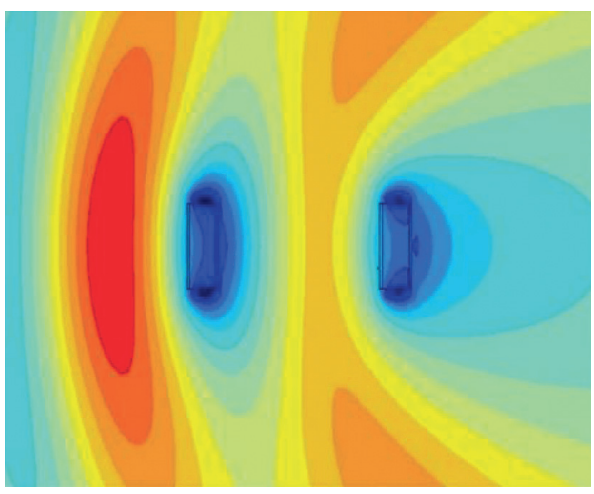

(h)

Figure 13: Wave pattern contour around different FBWs: (a) plus-shaped, $T=4 \mathrm{~s}$; (b) plus-shaped, $T=10 \mathrm{~s}$; (c) $\pi$-shaped, $T=4 \mathrm{~s}$; (d) $\pi$-shaped, $T=10 \mathrm{~s}$; (e) triangular-shaped, $T=4 \mathrm{~s}$; (f) triangular-shaped, $T=10 \mathrm{~s}$; (g) box-shaped, $T=4 \mathrm{~s}$; (h) box-shaped, $T=10 \mathrm{~s}$. 


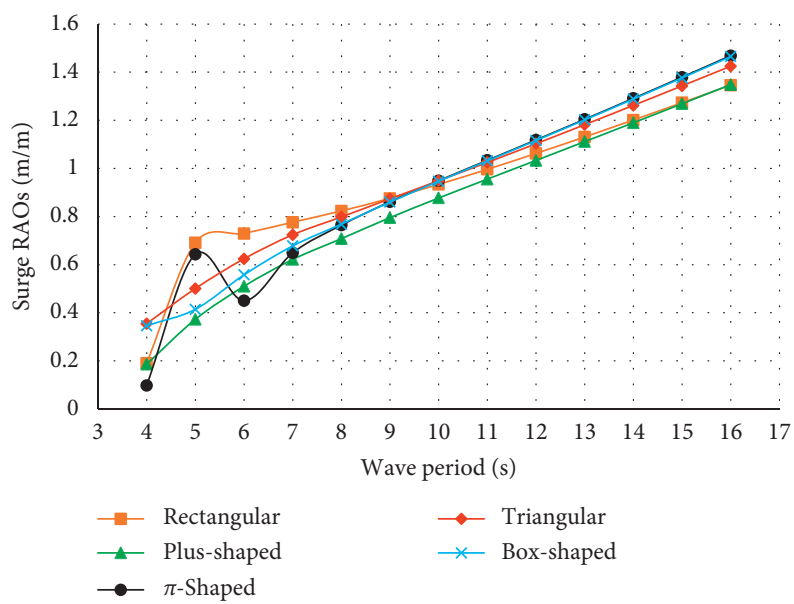

Figure 14: The frequency response of the surge RAO for the different FBWs.

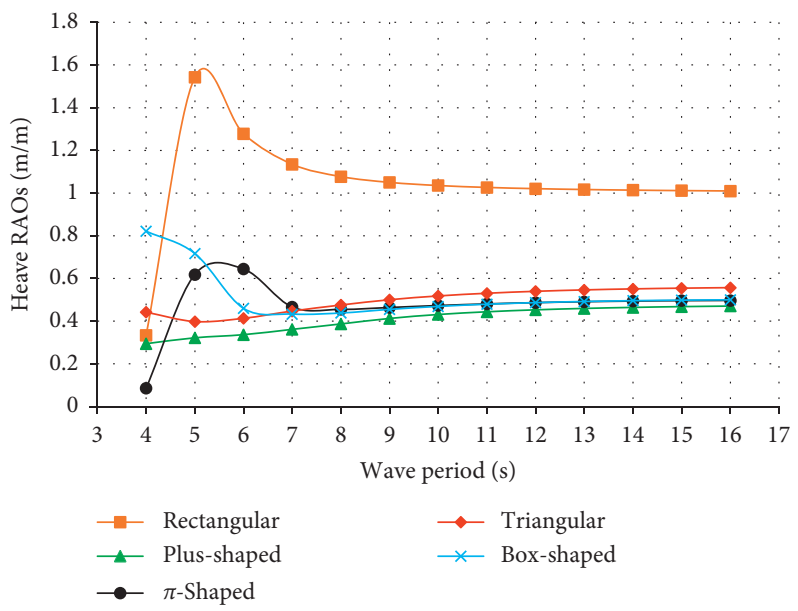

FIgURE 15: The frequency response of the heave RAO for the different FBWs.

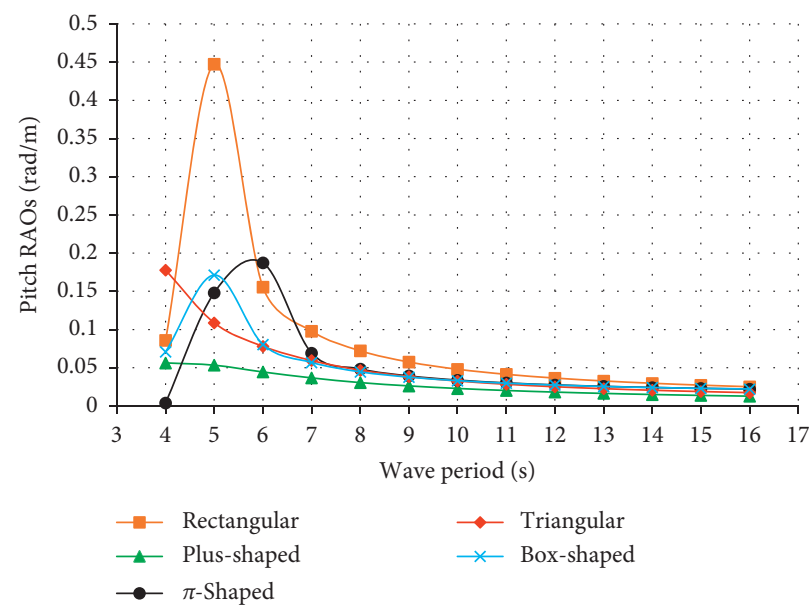

FIGURE 16: The frequency response of the pitch RAO (radian per meter) for the different FBWs.

$10 \mathrm{~s}$ and can reduce the wave height in this period as well. These cases (Figures 11-13) prove the accuracy of the results that were shown in Figure 10.
4.3. Motion Responses of FBWs. The role of structural motion responses for different configurations is examined in the frequency and time domains. Here, the responses in the 


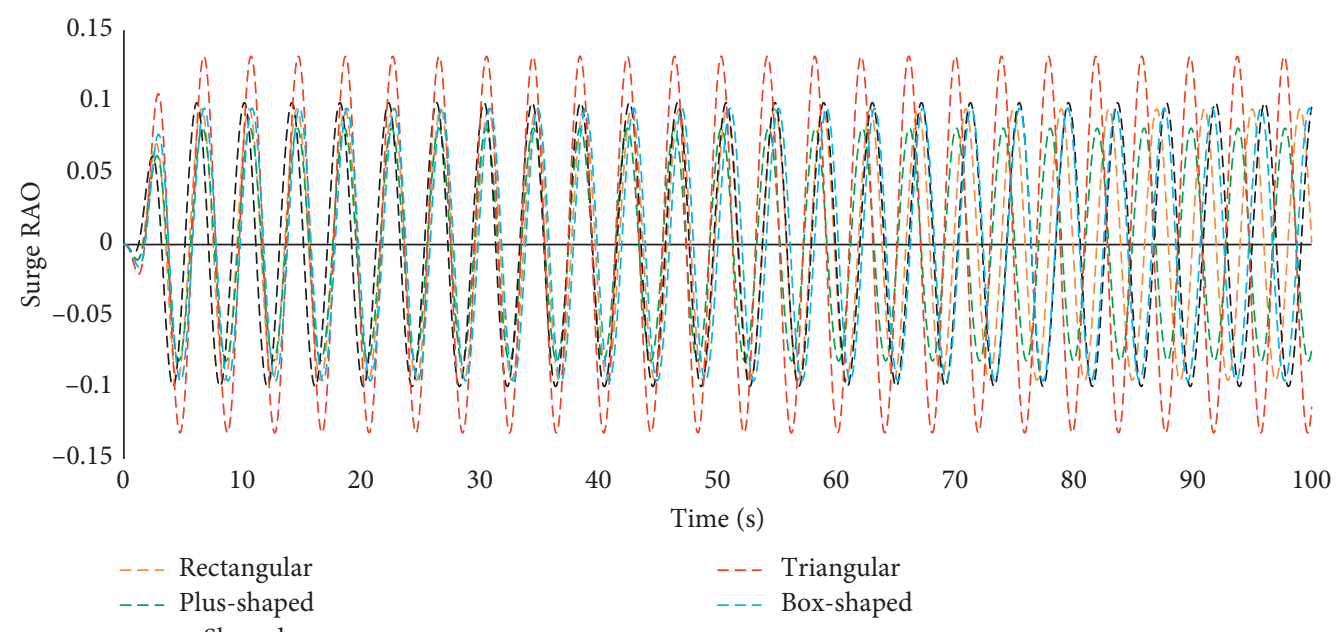

(a)
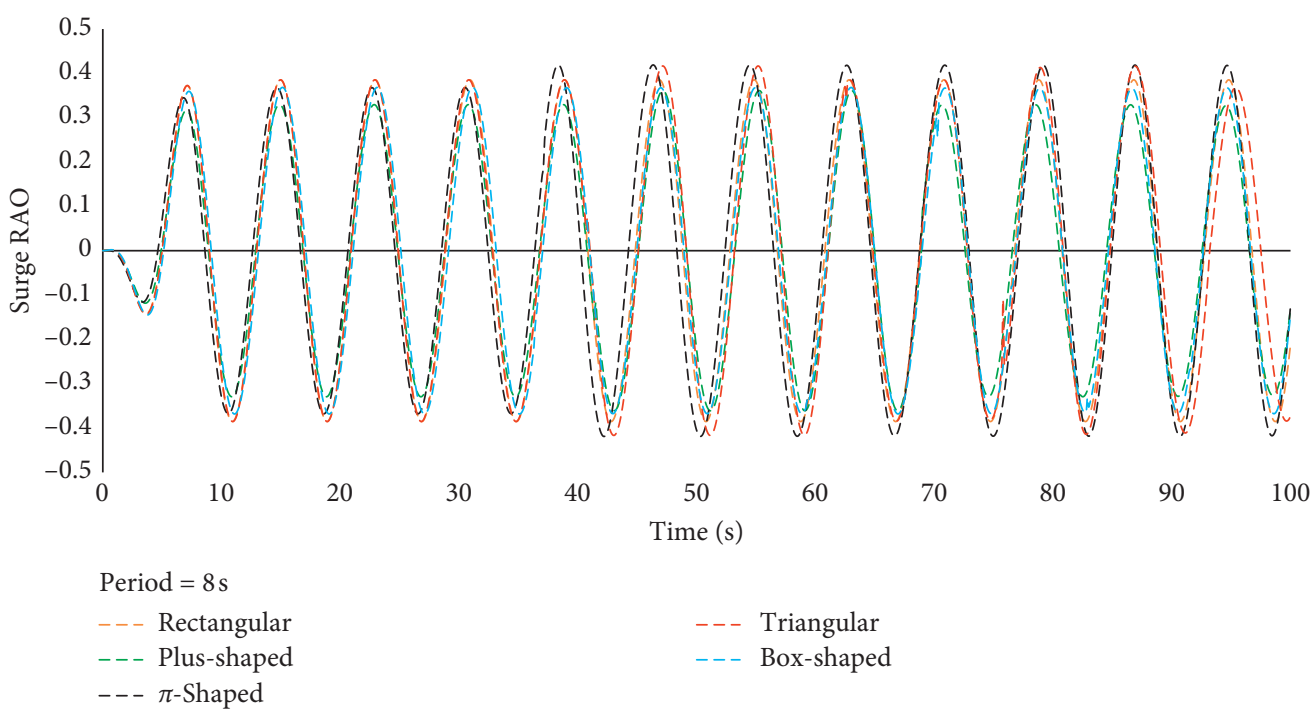

--- Triangular

--- Box-shaped

(b)

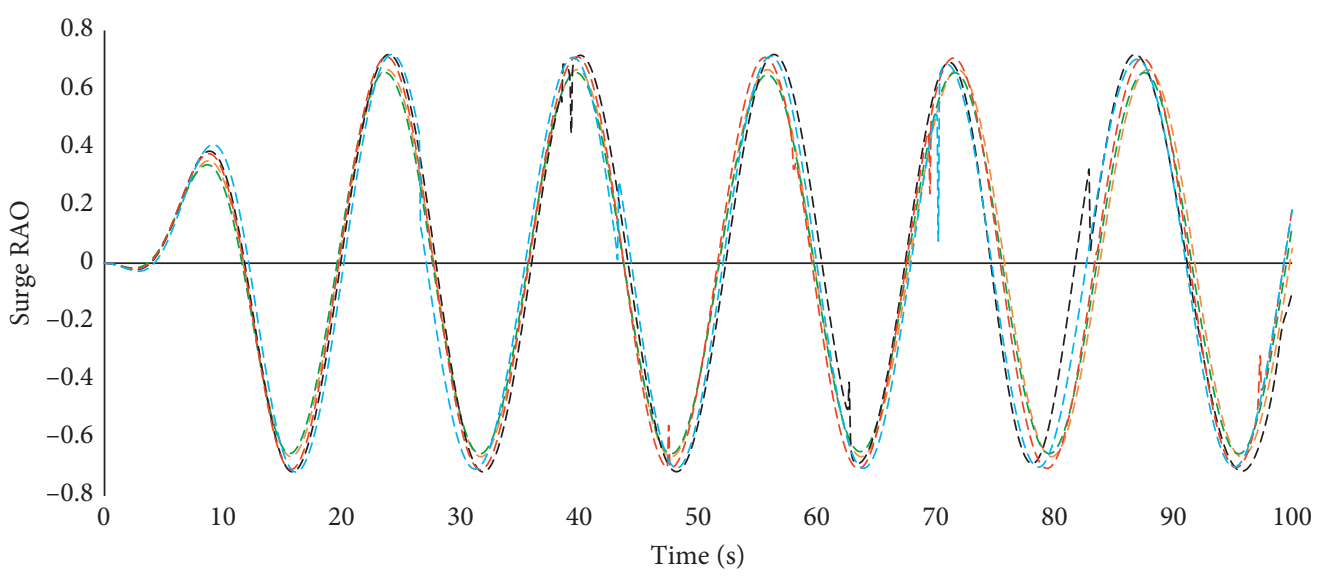

Period $=16 \mathrm{~s}$
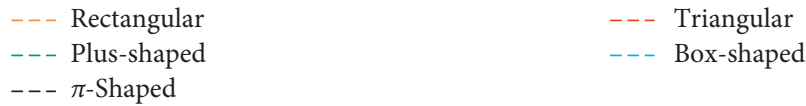

(c)

FIgURE 17: Time response of the surge RAO for the different FBWs at three periods. 


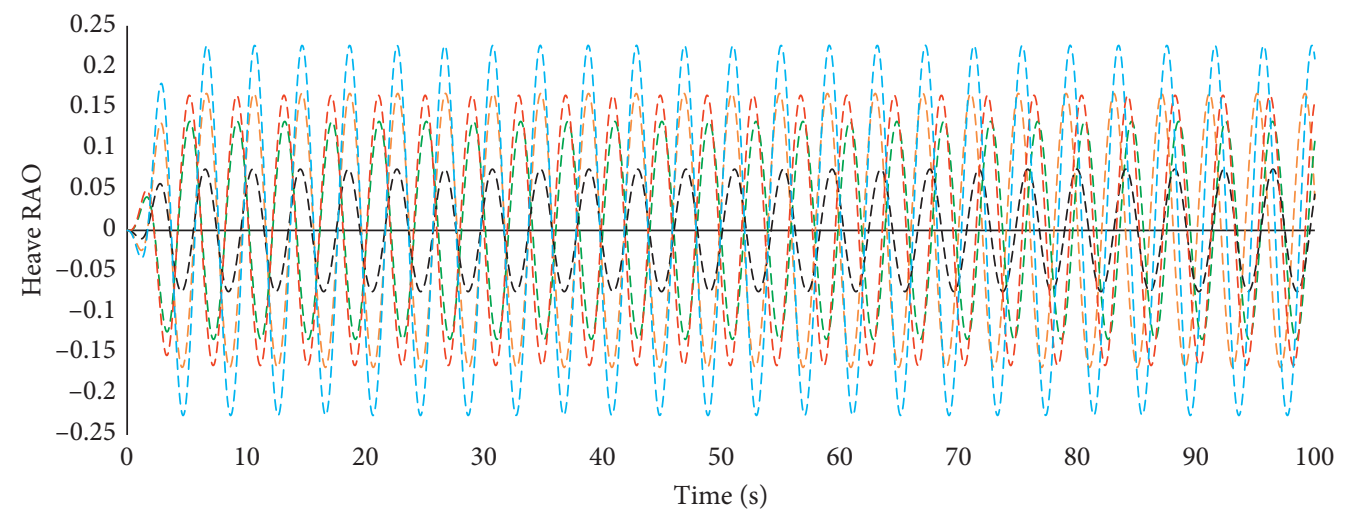

Period $=4 \mathrm{~s}$

- Rectangular
- - Plus-shaped

- - Triangular

$--\pi$-Shaped

(a)

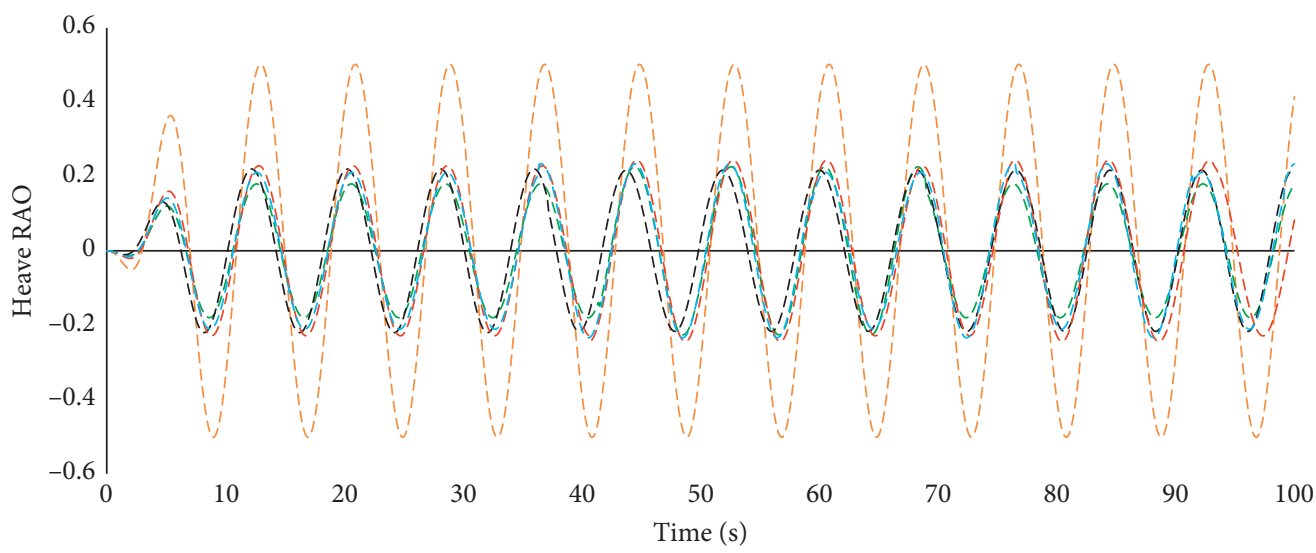

Period $=8 \mathrm{~s}$

- - Rectangular

- - - Plus-shaped

- - Triangular

- - $\pi$-Shaped

(b)

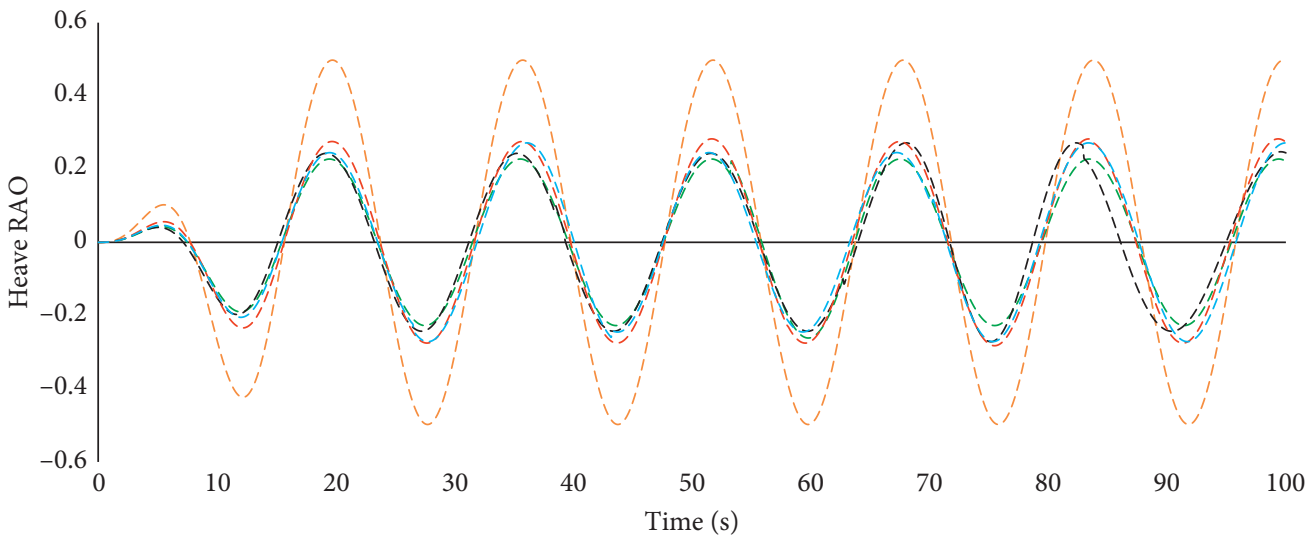

Period $=16 \mathrm{~s}$

-- Rectangular

-- - Plus-shaped

- - Triangular

$--\pi$-Shaped

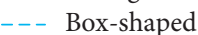

(c)

FIgURE 18: Time response of the heave RAO for the different FBWs at three periods. 


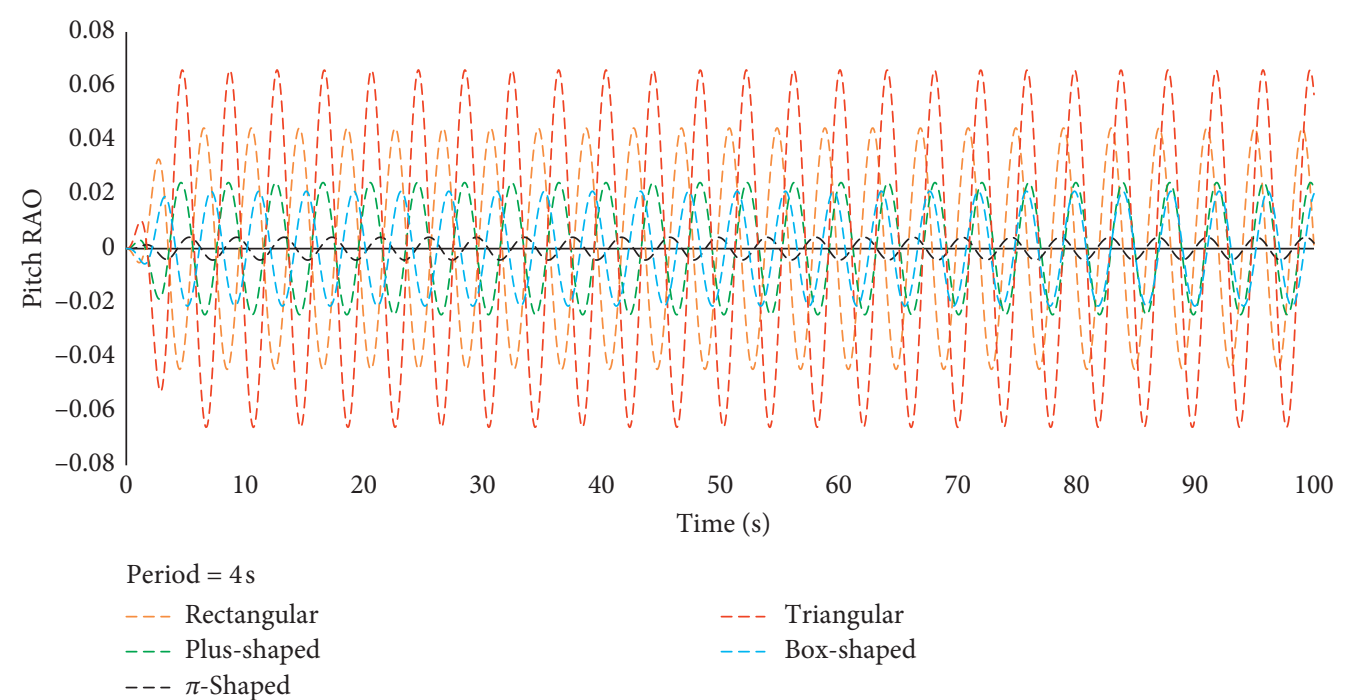

(a)

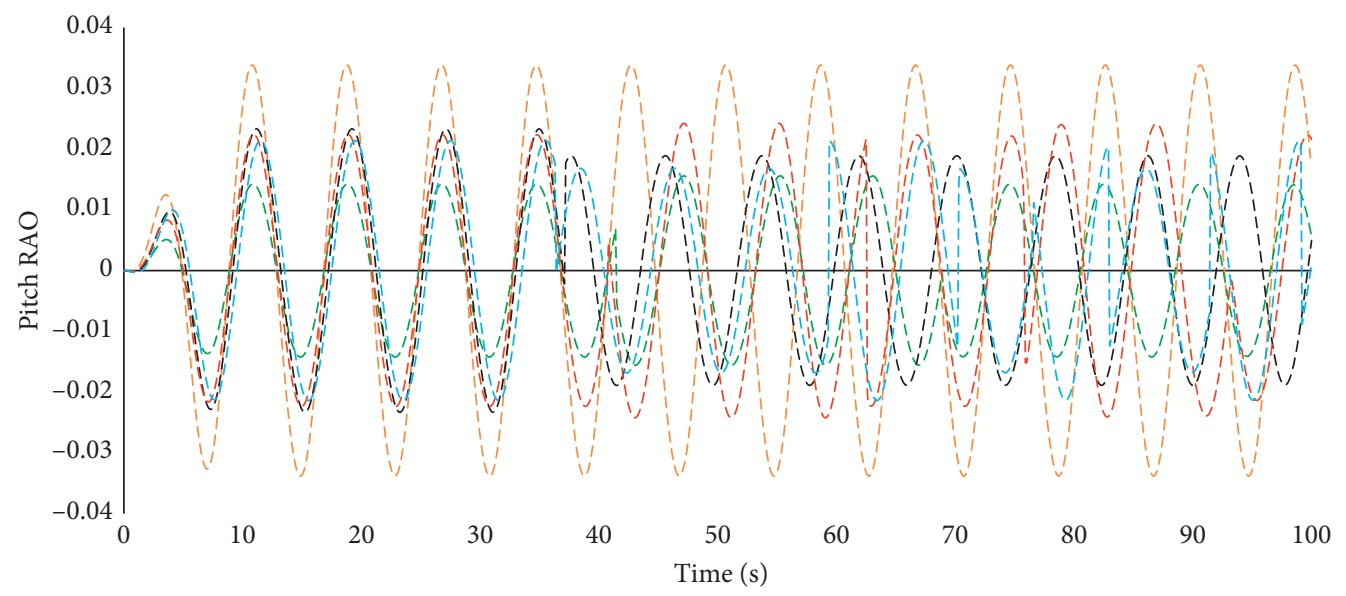

Period $=8 \mathrm{~s}$

--- Rectangular

-. - Plus-shaped

$--\pi$-Shaped

-_- Triangular
-_- Box-shaped

(b)

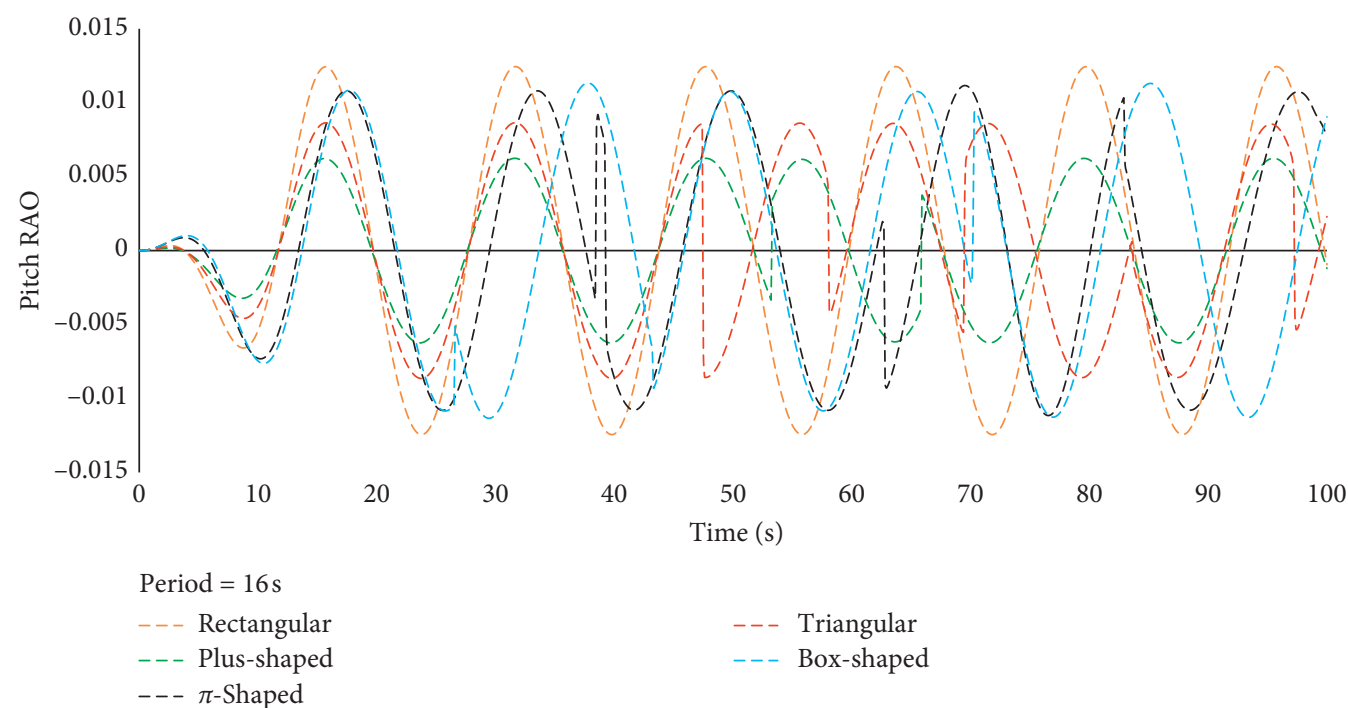

(c)

FIgURE 19: Time response of the pitch RAO (radian per meter) for the different FBWs at three periods. 


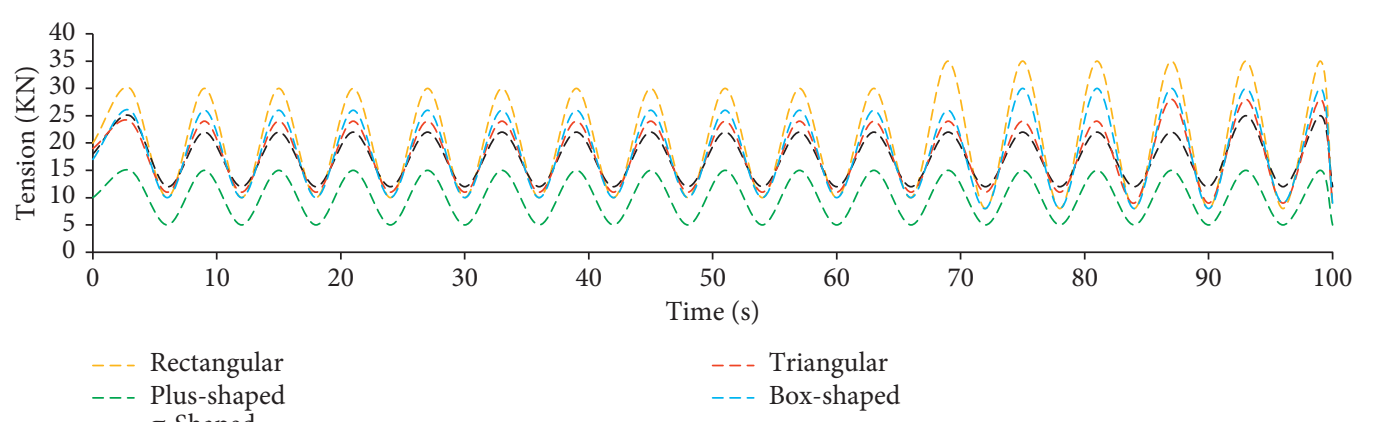

(a)

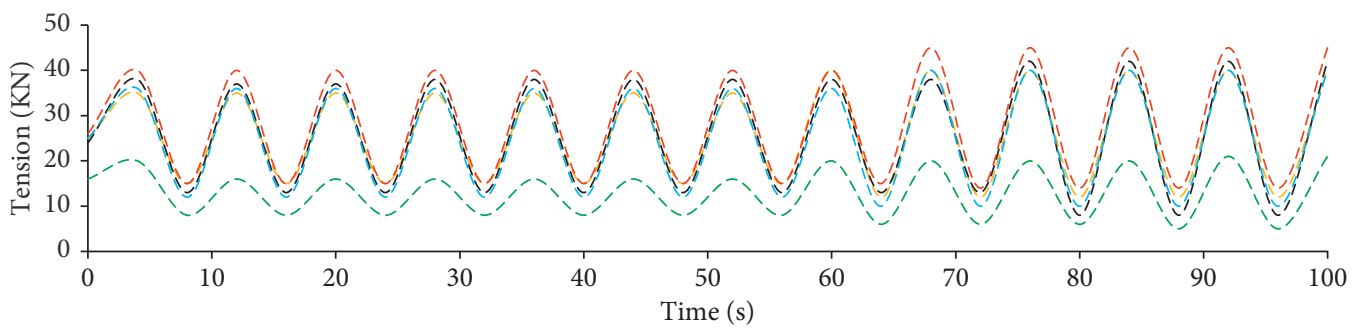

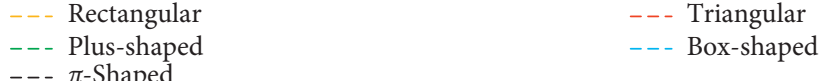

(b)

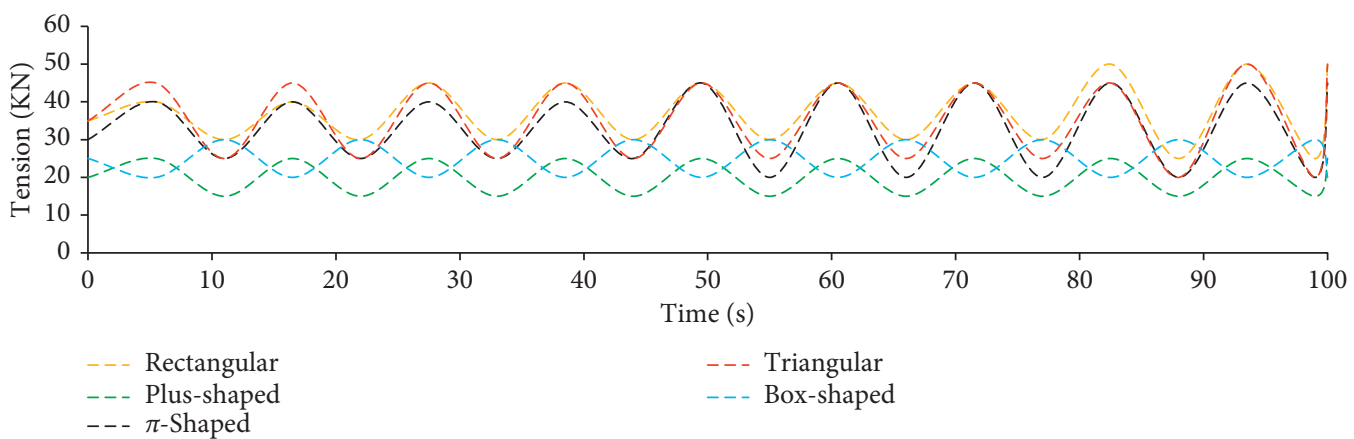

(c)

Figure 20: FBWs time response of mooring line tension for different shapes at three periods of $4 \mathrm{~s}, 8 \mathrm{~s}$, and $16 \mathrm{~s}$.

surge, heave, and pitch modes are reported. Figures 14-16 show RAO of the surge, heave, and pitch motions in the frequency domain for five shapes of FBWs. The frequency analysis results show that the increase of the period increases the motion. There are some critical results in a low-wave period of heave and pitch RAOs for rectangular FBW. Heave and pitch RAOs of rectangular FBW are shown in Figures 15 and 16, respectively. The results of the rectangular FBW show that the RAO is increased significantly in the period of $5 \mathrm{~s}$. For heave motion, the increase in RAO reduces slightly but then follows a steady process. For pitch motion, this increase in the period of $5 \mathrm{~s}$ reduces until it reaches the desired process. In the wave transmission analysis, the results of the rectangular FBW showed that, in the period of $5 \mathrm{~s}$, there is a significant increase in wave transmission. Also, in higher-wave periods, the wave transmission is high, and the rectangular FBW loses its performance. The reason for the increase in wave transmission in the rectangular FBW could be the increase in FBW oscillations shown in Figures 15 and 16. Actually, the wave energy increased by the floating breakwater motion. According to the equal conditions for all FBWs, this can be due to the geometry and displacement of the FBWs. In fact, the geometry and displacement of FBWs change the inertial term (added mass + structural mass) of the equation of motion of FBWs relative to each other. Frequency domain results show that the plus-shaped FBW has a stable process in all motions studied for all periods. The reason for the increase in wave transmission in the rectangular FBW could be the increase in FBW oscillations shown in Figures 14 and 16. Figures 17-19 show the time response of the RAO (surge, heave, and pitch) for the different FBWs at three periods of 4,8 , and $16 \mathrm{~s}$.

Simulation is performed for time of $100 \mathrm{~s}$ with step of $0.001 \mathrm{~s}$, and the incident wave height was $1 \mathrm{~m}$. The effect of shape and configuration ratio on the FBWs response is presented and discussed in the time domain. The results 
show that, at the period of $4 \mathrm{~s}$, triangular FBW at all three motions response and box-shaped FBW at the pitch motion have a bigger amplitude compared to rectangular FBW. There are some irregular motions observed for $\pi$-shaped, triangular, and box-shaped FBWs at periods of 8 and $16 \mathrm{~s}$, which is maybe due to instability at some periods. Based on the results in both frequency and time domains, the plusshaped FBW has a lower amplitude (RAO) and a more efficient and stable response at all periods.

4.4. Mooring Line Tension. Figure 20 shows the cable tension force histories for different shapes of FBWs at three periods (4, 8 , and $16 \mathrm{~s}$ ). In this study, the mooring tension calculation was carried out on the first cable of the rear FBW (Figure 2). The analyses are presented at a time of $100 \mathrm{~s}$ with step of $0.001 \mathrm{~s}$, and the incident wave height was $1 \mathrm{~m}$. The results show that the variation of geometry and the increase in the wave period do not have a significant effect on the tension of the cables. In the period of $4 \mathrm{~s}$, the cable tension of the rectangular FBW is more than those of the other FBWs. In the whole time, tension force oscillations were observed for all FBWs except the plus-shaped FBW, which showed good stability.

\section{Conclusion}

In this study, a numerical model is performed to analyze the hydrodynamic performance of the moored double-row FBWs in different shapes (rectangular, plus-shaped, $\pi$-shaped, triangular, and box-shaped). First, the numerical results of wave transmission coefficient and RAO responses were compared with experimental data. Then, five shapes of FBWs were selected to analyze the wave transmission coefficient, RAO, and mooring line tension. Based on the numerical results, the following conclusions can be drawn:

(i) The wave transmission coefficient and RAO response of the rectangular shape are compared with available experimental data, and the results showed good agreement between them under various wavelengths, wave height, and distances of doublerow FBW.

(ii) Among five FBWs configurations, the $\pi$-shaped, box-shaped, and plus-shaped FBWs have better performance regarding the wave transmission coefficient in high-wave periods. Although the rectangular FBW has a larger volume, it has an unfavorable performance.

(iii) Comparisons of motion responses showed that rectangular FBW has significant RAO response at all periods, while the plus-shaped FBW has less RAO.

(iv) The results of the mooring tension showed that the variations of geometry and the increase in the wave period do not have a significant effect on the tension of the cables, and the plus-shaped FBW has excellent stability in cable tension.

(v) In general, the plus-shaped FBW has better performance regarding $\mathrm{RAO}$ response, mooring tension, and wave transmission.

\section{Data Availability}

The data used to support the findings of this study are included within the article.

\section{Conflicts of Interest}

The authors declare that they have no conflicts of interest.

\section{References}

[1] C. Ji, Y. Cheng, K. Yang, and G. Oleg, "Numerical and experimental investigation of hydrodynamic performance of a cylindrical dual pontoon-net floating breakwater," Coastal Engineering, vol. 129, pp. 1-16, 2017.

[2] B. L. McCartney, "Floating breakwater design," Journal of Waterway, Port, Coastal, and Ocean Engineering, vol. 111, no. 2, pp. 304-318, 1985.

[3] S. A. Sannasiraj, V. Sundar, and R. Sundaravadivelu, "Mooring forces and motion responses of pontoon-type floating breakwaters," Ocean Engineering, vol. 25, no. 1, pp. 27-48, 1998.

[4] H. H. Lee, L.-Y. Chen, W.-K. Weng, and S.-W. Shyue, "The prediction of the dynamic and structural motions of a floating-pier system in waves," Ocean Engineering, vol. 34, no. 7, pp. 1044-1059, 2007.

[5] H. Y. Wang and Z. C. Sun, "Experimental study of a porous floating breakwater," Ocean Engineering, vol. 37, no. 5-6, pp. 520-527, 2010.

[6] E. Peña, J. Ferreras, and F. Sanchez-Tembleque, "Experimental study on wave transmission coefficient, mooring lines and module connector forces with different designs of floating breakwaters," Ocean Engineering, vol. 38, no. 10, pp. 1150-1160, 2011.

[7] F. He, Z. Huang, and A. Wing-Keung Law, "Hydrodynamic performance of a rectangular floating breakwater with and without pneumatic chambers: an experimental study," Ocean Engineering, vol. 51, pp. 16-27, 2012.

[8] T. Martin, A. Kamath, and H. Bihs, "Numerical simulation of interactions between water waves and a moored-floating breakwater," Coastal Engineering Proceedings, vol. 1, no. 36, p. 105, 2018.

[9] I.-H. Cho, "Transmission coefficients of a floating rectangular breakwater with porous side plates," International Journal of Naval Architecture and Ocean Engineering, vol. 8, no. 1, pp. 53-65, 2016.

[10] W. Peng, K.-H. Lee, S.-H. Shin, and N. Mizutani, "Numerical simulation of interactions between water waves and inclinedmoored submerged floating breakwaters," Coastal Engineering, vol. 82, pp. 76-87, 2013.

[11] W. Qiao, K. H. Wang, W. Duan, and Y. Sun, "Analytical model of wave loads and motion responses for a floating breakwater system with attached dual porous side walls," Mathematical Problems in Engineering, vol. 2018, Article ID 1295986, 2018.

[12] S. R. Samaei, F. Azarsina, and M. A. Ghahferokhi, "Numerical simulation of floating pontoon breakwater with ANSYS AQWA software and validation of the results with laboratory data," Bulletin de la Société Royale des Sciences de Liège, vol. 85, pp. 1487-1499, 2016.

[13] S. M. R. Tabatabaei and H. Zeraatgar, "Parametric comparison of rectangular and circular pontoons performance as floating breakwater numerically," Polish Maritime Research, vol. 25, no. s1, pp. 94-103, 2018. 
[14] C.-Y. Ji, X. Chen, J. Cui, O. Gaidai, and A. Incecik, "Experimental study on configuration optimization of floating breakwaters," Ocean Engineering, vol. 117, pp. 302-310, 2016.

[15] R. Cox, I. Coghlan, and C. Kerry, "Floating breakwater performance in irregular waves with particular emphasis on wave transmission and reflection, energy dissipation, motions and restraining forces," in Proceedings of the Conference: Coastal Structures 2007 - 5th Coastal Structures International Conference, CST07, pp. 351-362, Venice, Italy, July 2007.

[16] R. Cox and D. A. Beach, "Floating breakwater performancewave transmission and reflection, energy dissipation, motions and restraining forces," in Proceedings of the First International Conference on the Application of Physical Modelling to Port and Coastal Protection, pp. 371-381, Porto, Portugal, May 2006.

[17] Z. Huang, F. He, and W. Zhang, "A floating box-type breakwater with slotted barriers," Journal of Hydraulic Research, vol. 52, no. 5, pp. 720-727, 2014.

[18] Y. Ozeren, D. G. Wren, and C. V. Alonso, Experimental and Numerical Investigations of Floating Breakwater Performance, US Department of Agriculture, Agricultural Research Service, National Sedimentation Laboratory, MS, USA, 2009.

[19] E. Loukogeorgaki and D. C. Angelides, "Effect of mooring lines on floating breakwaters performance," in Proceedings of the Fifteenth International Offshore and Polar Engineering Conference, International Society of Offshore and Polar Engineers, Seoul, Korea, June 2005.

[20] Z. Deng, L. Wang, X. Zhao, and Z. Huang, "Hydrodynamic performance of a T-shaped floating breakwater," Applied Ocean Research, vol. 82, pp. 325-336, 2019.

[21] B. Ren, M. He, Y. Li, and P. Dong, "Application of smoothed particle hydrodynamics for modeling the wave-moored floating breakwater interaction," Applied Ocean Research, vol. 67, pp. 277-290, 2017.

[22] F. He, J. Leng, and X. Zhao, "An experimental investigation into the wave power extraction of a floating box-type breakwater with dual pneumatic chambers," Applied Ocean Research, vol. 67, pp. 21-30, 2017.

[23] I. Diamantoulaki, D. C. Angelides, and G. D. Manolis, "Performance of pile-restrained flexible floating breakwaters," Applied Ocean Research, vol. 30, no. 4, pp. 243-255, 2008.

[24] C. Ji, X. Deng, and Y. Cheng, "An experimental study of double-row floating breakwaters," Journal of Marine Science and Technology, vol. 24, no. 2, pp. 359-371, 2019.

[25] C.-Y. Ji, X.-Q. Bian, Y. Cheng, and K. Yang, "Experimental study of hydrodynamic performance for double-row rectangular floating breakwaters with porous plates," Ships and Offshore Structures, vol. 14, no. 7, pp. 737-746, 2019.

[26] Y. Ozeren, D. G. Wren, M. Altinakar, and P. A. Work, "Experimental investigation of cylindrical floating breakwater performance with various mooring configurations," Journal of Waterway, Port, Coastal, and Ocean Engineering, vol. 137, no. 6, pp. 300-309, 2011.

[27] P. Lin, Numerical Modeling of Water Waves, CRC Press, Boca Raton, FL, USA, 2008.

[28] J. Jin, "A mixed mode function-boundary element method for very large floating structure-water interaction systems excited by airplane landing impacts," Doctoral Dissertation, University of Southampton, Southampton, UK, 2007.

[29] N. D. Barltrop, Floating Structures: A Guide for Design and Analysis, vol. 1 and 2, The Centre for Marine and Petroleum Technology, Oilfield Publications Ltd, Herefordshire, UK, 1998, ISBN: 1870553 357, Publication 101/98.
[30] J. N. Newman, "The theory of ship motions," Advances in Applied Mechanics, vol. 18, pp. 221-283, 1979.

[31] T. H. Havelock, "Waves due to a floating sphere making periodic heaving oscillations," Proceedings of the Royal Society of London. Series A. Mathematical and Physical Sciences, vol. 231, no. 1184, pp. 1-7, 1955.

[32] W. E. Cummins, The Impulse Response Function and Ship Motions (No. DTMB-1661), David Taylor Model Basin, Washington DC, USA, 1962.

[33] W. Duan, S. Xu, and Q. Xu, R. C. Ertekin and S. Ma, Performance of an F-type floating breakwater: a numerical and experimental study," Proceedings of the Institution of Mechanical Engineers, Part M: Journal of Engineering for the Maritime Environment, vol. 231, no. 2, pp. 583-599, 2017. 